\title{
Managing formalization to increase global team effectiveness and meaningfulness of work in multinational organizations
}

\author{
Cristina B Gibson ${ }^{1}$, \\ Patrick D Dunlop ${ }^{2}$ and \\ John L Cordery ${ }^{3}$
}

\footnotetext{
${ }^{1}$ Pepperdine Graziadio School of Business, Pepperdine University, 6100 Center Drive, Los Angeles, CA 90045, USA; ${ }^{2}$ Future of Work Institute, Faculty of Business and Law, Curtin University, Kent Street, Bentley, WA 6102, Australia; ${ }^{3}$ Curtin University, Perth, Australia

Correspondence:

CB Gibson, Pepperdine Graziadio School of Business, Pepperdine University, 6100 Center Drive, Los Angeles, CA 90045, USA.

Tel: 1-949-656-9804;

e-mail: cristina.gibson@pepperdine.edu
}

\begin{abstract}
Global teams may help to integrate across locations, and yet, with formalized rules and procedures, responsiveness to those locations' effectiveness, and the team members' experiences of work as meaningful may suffer. We employ a mixed-methods approach to understand how the level and content of formalization can be managed to resolve these tensions in multinationals. In a sample of global teams from a large mining and resources organization operating across 44 countries, interviews, observations, and a quantitative 2-wave survey revealed a great deal of variability between teams in how formalization processes were enacted. Only those formalization processes that promoted knowledge sharing were instrumental in improving team effectiveness. Implementing rules and procedures in the set-up of the teams and projects, rather than during interactions, and utilizing protocols to help establish the global team as a source of identity increased this knowledge sharing. Finally, we found members' personal need for structure moderated the effect of team formalization on how meaningful individuals found their work within the team. These findings have significant implications for theory and practice in multinational organizations.
\end{abstract}

Journal of International Business Studies (2019) 50, $1021-1052$.

https://doi.org/10.1057/s41267-019-00226-8

Keywords: qualitative/quantitative comparisons; survey method; teams and teamwork; knowledge acquisition and sharing; integration and responsiveness

The online version of this article is available Open Access

\section{INTRODUCTION}

Multinational organizations (MNOs) are replete with integrative challenges, as geographically dispersed employees engage in global work, collaborating across different political, economic, societal, and cultural contexts. In response to those challenges, many firms deploy global teams, defined as bounded structures, formally recognized by the organization as teams, with members who work across national boundaries, and who are collectively accountable for outputs across locations (Hinds, Liu \& Lyon, 2011). Such global teams often serve as mechanisms for integrating core
Received: 22 September 2017

Revised: 28 September 2018

Accepted: 16 December 2018

Online publication date: 17 March 2019 
operations across the locations represented in the teams, and it is this feature of their work that serves as their most important defining characteristic (Cramton \& Hinds, 2014; Gibson, Huang, Kirkman \& Shapiro, 2014). In many MNOs, it is the global nature of the team that drives the need to put formal processes in place to coordinate activity and ensure participation across global locations, but these teams also need to maintain flexibility and allow for emergent processes to address issues that arise at a local level (Raisch \& Birkinshaw, 2008; Gibson \& Dibble, 2013; Cordery, Soo, Kirkman, Rosen \& Mathieu, 2015).

Managing the degree of formalization in global teams, defined as the codified rules, policies, and procedures to shape behavior, guide actions, and govern social positions and role relationships between individuals (e.g., Chen \& Huang, 2007; Hempel, Zhang, \& Han, 2012; Hirst, Van Knippenberg, Chen, \& Sacramento, 2011), is a means of navigating the dual needs of coordination and flexibility in MNOs. Decisions regarding formalization are highly impactful - formalization can increase accountability and commitment, and yet destroy the very essence of a team's appeal to its members, reducing members' well-being at work, and the overall ability of the team to contribute to the organization's objectives. The weight of empirical evidence regarding traditional teams (i.e., colocated and engaging in core operations) seems to suggest that more formalization is better than less, because it helps facilitate information exchange and task allocation (Bunderson \& Boumgarden, 2010). However, we lack research on the new global team forms that are so central to MNOs, in which the relationship between formalization and effectiveness is likely to be complex and multi-layered, and must reflect a responsiveness to the crosslocation nature of membership and tasks (Crawford \& LePine, 2013; Adler \& Borys, 1996).

To develop and test a multi-level theory of formalization in MNOs, we conducted a comprehensive mixed-method study, examining how formalization, mandated at the organizational level, was implemented and experienced at the team and individual levels, ultimately affecting both the ability of the teams to achieve the organization's objectives and the meaningfulness of the work across the global sites. Meaningfulness of work is the members' experience of their daily work responsibilities as having broader significance (Rosso, Dekas \& Wrzesniewski, 2010), and has been reported by employees to be more important for their well-being than any other occupational feature, including income, job security, and the opportunity for career advancement (Cascio, 2003; Carton, 2018). Meaningfulness of work predicts life satisfaction, happiness, and work enjoyment (Bonebright, Clay, \& Ankenmann, 2000). Yet this individual outcome may be challenged by global work due to its complex and geographically dispersed nature. We focus on the global feature of the teams as their defining characteristic, and we show that, even after controlling for communication technology use, formalization in the structure of the teams was critical to their success. Specifically, it enabled them to be effective in ways that were responsive to the uniqueness of locations represented on the teams, and by contributing to members' experience of their work as meaningful. The study's design allowed us to revisit basic assumptions that have prevailed in the literature, revealing the multi-level complexity of formalization in MNOs.

\section{LITERATURE REVIEW}

Three key formalization challenges are at the core of effectiveness and meaningfulness of global teamwork in MNOs: (1) utilizing formalization policies at the organizational level to balance global integration and local responsiveness across teams; (2) utilizing formalization implementation processes among teams to create cohesion, whilst allowing sufficient informality for diverse knowledge to flow; and (3) utilizing formalization to drive engagement and meaning within the team, while at the same time recognizing individual differences and fulfilling diverse needs. Given these challenges are at different levels, each is informed by a different body of literature, which we review below. Developing our multi-level theory of formalization thus serves to integrate these currently disparate areas of the literature (see Figure 1).

\section{Formalization that Prioritizes Integration Over Local Responsiveness}

A key tension in MNOs is that between the need for both global integration and local responsiveness (Doz, Bartlett \& Prahalad, 1981; Bartlett \& Ghoshal, 1989; Roth \& Morrison, 1991; Johnson, 1995). Since its introduction, the integration-responsiveness framework has been refined and applied by many researchers (e.g., Devinney, Midgley \& Venaik, 2000; Luo, 2001; Zellmer-Bruhn \& Gibson, 2006), underscoring the need for MNOs to balance 


\begin{tabular}{|c|c|c|}
\hline Formalization Tensions & Focal Connections & Literature Base \\
\hline $\begin{array}{l}\text { Formalization that Prioritizes } \\
\text { Integration over Local } \\
\text { Responsiveness }\end{array}$ & Organization to Teams & $\begin{array}{l}\text { - Internationalization } \\
\text { (Devinney, Midgley \& } \\
\text { Venaik, 2000; Martinez \& } \\
\text { Jarillo, 1991) } \\
\text { - Strategic Tensions (Raish \& } \\
\text { Birkinshaw, 2008; Zellmer- } \\
\text { Bruhn \& Gibson, 2006) }\end{array}$ \\
\hline $\begin{array}{l}\text { Formalization for Team } \\
\text { Cohesion at the Expense of } \\
\text { Diverse Team Knowledge } \\
\text { Flows }\end{array}$ & Between and $\mathrm{Wi}$ & $\begin{array}{l}\text { - Team Design (e.g., Hempel, } \\
\text { Zhang, \& Han, 2012; } \\
\text { Crawford \& LePine, 2013) } \\
\text { - Team Knowledge Sharing } \\
\text { (Cramton, 2001; Sole and } \\
\text { Huysman, 2000) }\end{array}$ \\
\hline $\begin{array}{l}\text { Formalization That Allows for } \\
\text { Meaningful Work Amidst } \\
\text { Individual Differences }\end{array}$ & Team to Individual & $\begin{array}{l}\text { - Individual Differences (e.g, } \\
\text { Hurst et al. 2011; LePine et } \\
\text { al. 2011) } \\
\text { - Meaningful Work (e.g,. } \\
\text { Dimitrov, 2011; Barrick, } \\
\text { Mount, \& Li, 2013; Carton, } \\
\text { 2018) }\end{array}$ \\
\hline
\end{tabular}

Figure 1 Multi-level framework for formalization challenges in MNOs.

the ability of differentiated local subsidiaries to meet unique local demands, with the requirement to provide integration, control, and coordination of the entire organization (Takeuchi \& Porter, 1986; Schreyögg \& Sydow, 2010). Increasingly, the role of teams in addressing such tensions has been recognized (Lubatkin, Simsek, Ling, \& Veiga, 2006; Jansen, Van den Bosch, \& Volberda, 2006; Jansen, Tempelaar, Van den Bosch, \& Volberda, 2009; Haas 2010).

Emphasizing global integration promotes a holistic view of global operations and explicitly coordinates interdependent processes and products across subsidiaries. For instance, to maintain cost efficiencies, MNOs increase control through centralization of decision making. However, in doing so, they create parameters within which subsidiaries can act, thus constraining innovation. In contrast, emphasizing local responsiveness helps maximize initiative and proactive pursuit of new business opportunities (Luo, 2001; Birkinshaw, 1996), and allows managers to reap benefits from local customers, suppliers, distributors, competitors, and governmental authorities, which in turn creates more competitive opportunities (Ghoshal \& Nohria, 1989).
Formalization of rules, policies, and procedures helps to ensure coordination and can therefore increase global integration, but it may also serve to reduce the flexibility that is often required to tailor practices such that they suit each location (Martinez \& Jarillo, 1991; Eisenhardt, Furr, \& Bingham, 2010; Kortmann, Gelhard, Zimmermann, \& Piller, 2014). Scholars seem to agree that formalization could be an important tool for MNOs in the process of managing tensions (Eisenhardt et al., 2010), but what remains unclear are the mechanisms by which the formalization intended for this purpose at the organizational level can be successfully implemented across and through various levels of the MNO (Junni, Sarala, Taras, \& Tarba, 2013).

Global teams may be able to serve as this mechanism, translating the organizational policies into action; however, research suggests that, even when faced with the same organizational policies, teams may nonetheless enact and implement organizational rules, policies and procedures in different ways (Orlikowski, 2000; Hirst et al., 2011; Haas, 2010). That is, although an organization might stipulate the introduction of particular formalized processes, the manner in which these changes manifest themselves at the front line can vary considerably; thus, the intended or mandated 
structure is not the same as the resultant or enacted structure.

For example, organizations may make available a variety of information technologies that global teams can use to communicate and conduct their work. Yet not all global teams are highly dependent on communication technology, with some preferring to conduct their work face-to-face as much as possible. Being 'global' and being 'technologydependent' are not synonymous. Indeed, Gibson and Gibbs (2006) found that, just because a global team was geographically dispersed, it did not follow that the members interacted primarily using the communication technology tools mandated by the organization. Although some global teams are also technology-dependent, others primarily meet faceto-face. Organizational policies may advise teams in the use of information technology, such as an organization suggesting that members connect regularly using a conference call; however, the manner in which these calls are enacted may vary dramatically from team to team, in terms of the frequency of the calls, who participates in them, or which tools are used to support the call (e.g., phone or video, scheduling tools, presentation software, or a knowledge repository).

Having the freedom to make decisions about the nature and level of formalization that applies in a team is likely advantageous. For example, Bresman and Zellmer-Bruhn (2013) found that organizational mandates typically had adverse effects at the team level, except when teams had very little of their own team-level protocols (i.e., schedules, processes, rules, and procedures). An important implication of Bresman and Zellmer-Bruhn's study is that multiple organizational levels should be taken into consideration when assessing the effects of level of formalization, as well as processes of implementation (Kirkman, Mathieu, Cordery, Rosen, \& Kukenberger, 2011). To understand these, we must turn to literature which examines social and cognitive processes that occur within and between global teams.

\section{Formalization for Team Cohesion at the Expense of Diverse Team Knowledge Flows}

In global teams, capturing the attention of members is often difficult, given that members' focus is diluted by their local tasks and priorities and by their membership on other teams within their own local site (Klein \& Kleinhanns, 2001; Metiu \& Rothbard, 2013). Cordery, Soo, Kirkman, Rosen and Mathieu (2009) describe the challenge of trying to build team engagement when members collaborate across nationally dispersed sites, making it difficult to sustain knowledge flows in the face of competing role demands. A logical solution to such a challenge might be to increase the social connections between members, that is, to build the cohesion of the team, defined as the degree to which the attractiveness and prestige of the group, the members within it, or the activities of the group create a force acting on the members to remain active within it (Festinger, Schachter, \& Back, 1950: 254).

Formalization, to the extent that it clarifies roles and provides clear team boundaries, helps build identity and cohesion, without which global teams may struggle to effectively coordinate and prioritize their work activities. Examining more traditional, co-located work teams, several studies have found that the degree to which activities and tasks performed by the team are formalized is positively associated with a range of beneficial team processes, including reduced conflict and heightened psychological safety (Bunderson \& Boumgarden, 2010), which suggests that formalization might enhance global team effectiveness. Yet, creating cohesion through the imposition of bureaucratic structure to a global team's functioning may bring with it numerous unintended consequences, including restricting the free flow of knowledge and information that is dispersed in its culturally and experientially diverse membership. Doing so may impede the global team's ability to fulfill the purpose it was intended to provide, namely, to include the unique perspectives and practices from each of the different national locations which members represent (Courtright, Thurgood, Steward, \& Pierotti, 2015; Severt \& Estrada, 2015). Hence, an important tension exists between the need to formalize global teams, so as to create the cohesion and stability necessary to secure ongoing commitment and reliable performance, and the need to maintain the team's ability to be responsive to each location represented on the team and how it operates (Gibson \& Gibbs, 2006). With too much formalization, the teams risk losing the capacity to be agile and responsive and to learn in dynamic and complex operating environments (Zellmer-Bruhn \& Gibson, 2006).

Thus, increasing formalization carries both potential benefits and costs (Crawford \& LePine, 2013). The existence of some formally prescribed rules and procedures governing the scheduling and conduct of a team's work is likely to help clarify 
expectations, improve task coordination, and regulate conflict. However, increasing formalization also carries with it the risk of increasing constraints on opportunism, creativity, and location responsiveness. It is in this context that questions arise concerning how global team members react to the formalization of activities within their teams.

\section{Formalization that Allows for Meaningful Work Amidst Individual Differences}

A third key question for work in global teams pertains to whether being a member of such teams enriches the working lives of participants and, in particular, how the meaningfulness of such work is impacted by organizational attempts to regulate how such teams function. Research has explored various ways in which formalization could be enabling for individuals in situations such as this, across diverse settings such as restaurant chains (Ahrens \& Chapman, 2004), logistics departments (Wouters \& Wilderom, 2008), and software development (Adler, McGarry, Irion-Talbot, \& Binney, 2005; Hempel et al., 2012). These studies suggest that formalization is enabling to the extent that it provides individuals with guidance, goal clarity, or direction, without reducing flexibility in the manner in which an individual is able to execute their job (Hempel et al., 2012). Likewise, when managers indicate that formalized procedures are intended as guidelines, and stress the need to support the creativity and commitment of employees, formalization is more likely to be perceived as enabling (Ahrens \& Chapman, 2004). For example, citing the specific example of a performance measurement system, Wouters and Wilderom (2008) found that even a formalized control system could be perceived as enabling, when accompanied by experience-based processes and experimentation.

Importantly, however, Adler (2012) asserts that it is only when employees have the power to influence formalization, participating in how it is deployed, that it will serve social, productive ends. This constitutes another delimma of formalization. Specifically, in regard to individual outcomes such as meaningfulness of work, it will be difficult for employees to construct a connection between their work and a broader significance when the employees' responsibilities are relatively fixed and subject to managerial dictates or other organizational constraints (Carton, 2018). Hence, it makes sense that formalization that simultaneously provides enough flexibility for employees to exercise reasonable autonomy in respect of their own work, while also enabling effective coordination and generating a sense of collective purpose (Carton, Murphy, and Clark, 2014), will result in that work being seen as more meaningful by the globally dispersed members.

While there is clearly a need for a more in-depth understanding of how formalization might contribute to whether or not global teamwork is experienced as meaningful by team members, there is also the question of how individual differences between team members might influence such processes. For example, recent research examining knowledge flows in dyads has indicated that individual differences loom large in determining the motivation to engage in knowledge-sharing processes in teams (Quigly, Tesluk, Locke \& Bartol, 2007), and global teams often have membership that is more diverse and fluid than other types of teams (Gibson et al., 2014). Hence, overformalization is likely to pose a particular risk for members of global teams whose effectiveness is determined by the extent to which they share or manage knowledge (Caldwell \& O'Reilly, 2003; Pertusa-Ortega, Zaragoza-Saez, \& Claver-Cortes, 2010).

To develop theory addressing these three challenges, we began with the general research question, "How can the benefits of formalization be optimized and the liabilities reduced in global teams to enhance global work for the benefit of multinational organizations and global workers?" We turn next to our mixed-method examination of this question.

\section{STUDY 1. EXPERIENCES OF FORMALIZATION IN GLOBAL TEAMS}

\section{Study 1. Context, Sample, and Procedure}

We began our investigation with a qualitative study in order to develop a more precise understanding of the experience of formalization in global teams (Gibson, 2017). With this objective in mind, we conducted a series of interviews with members of global teams, recorded their teleconference calls, and observed their meetings. Participants in this study were employees of a large multinational mining and minerals processing firm, headquartered in the United States but with operations in over 44 countries. The teams in our sample were global teams that operated across national boundaries, and were bounded structures, formally recognized by the organization as global teams, and with members collectively accountable for specific 
outputs, hence adherng to the defining features of global teams in the literature (Hinds, Liu \& Lyon, 2011; Cramton \& Hinds, 2014). However, it is worth noting that members participated in these teams alongside their operational responsibilities within the processing plants.

By the time of our study, the global teams had become core to the functioning of the organization, in that they had developed critical operational efficiencies. Within a team, members were drawn from a common functional area, most typically representing a phase in the production process, but team members were from different locations across the globe (i.e., different plants). Hence, members within a team shared technical expertise, but each member had different local knowledge of their respective plant, and their facilities were embedded within different geographic contexts. In approaching their work, the global teams faced substantial localization pressures, in that the refineries in each location were embedded in very different norms, policies, procedures and protocols that often had cultural and institutional foundations based on the local context. Specifically, each team contained members from plants located in six countries (Australia, Brazil, Jamaica, Spain, Suriname, and the U.S), and the teams consisted of two employees per plant, one of whom served as a team facilitator (there were no formal team leaders). Given that the teams had the same degree and configuration of national diversity, the same level of geographic dispersion, and the same access to technologies, this helped us to rule out variance on these features as alternative explanations for our findings, an important step in conducting team research across cultures (Gibson et al., 2014). Such consistent team composition in a field setting is very rare in the research literature; we know of no other field study that offered such controls. The teams did vary in the extent to which they utilized various communication technologies, with some primarily meeting only when they had the opportunity to be face-to-face, and others making extensive use of instant messaging, email, knowledge repositories, scheduling software, and teleconferencing. Hence, on the continuum of virtuality (Gibson \& Gibbs, 2006), some of the teams could be considered highly virtual, while others were less virtual. Given this variability, we included communication technology use as a control in our analysis.

All the teams had been initiated at the same time for the same purpose, tasked specifically with sharing, integrating, and managing their respective local knowledge to generate organizational 'best practices' that would ultimately improve productivity across the firm. Similar to definitions in the knowledge management literature (e.g., Szulanski, 1996), the firm considered a best practice to be one that is deemed superior to internal alternate practices and known alternatives outside the firm. Furthermore, best practices in this context had to be applicable across locations. The best practices often pertained to innovative operational procedures, and, once identified and agreed upon, they were codified into a set of work instructions describing how personnel needed to interact with a process across different locations. Hence, developing these practices often required a high degree of creativity, and many new processes were implemented as a result of the work of these global teams. Although some of the practices related to technical operations, others involved employee roles and processes. Hence, the deliverables addressed by the teams were varied in content and nature.

To achieve the goal of developing such operational improvements, work within the teams entailed members discussing with others how they undertake certain functions across different locations, sharing ideas in order to innovate 'best practices', codifying these in the firm's knowledge repository, and then promoting the implementation of these superior innovative operational procedures. Most of this work was undertaken during teleconference meetings held twice a month, with these meetings being supplemented by discussion boards, email listserv exchanges, instant messaging and face-to-face meetings of team members.

The team's facilitator and at least 2-3 other members of each team were included in our interviews, which were conducted face-to-face on location and typically lasted $1 \mathrm{~h}$. The interview protocol (available from the authors upon request) contained questions about team composition, structure, processes, and outcomes. Members were also encouraged to provide examples, illustrations, and narratives about specific meetings, conversations, and exchanges that had occurred in their team. Due to availability constraints, the final interview sample consisted of 71 members from 16 teams; nevertheless, the sample was representative of team members' diversity of location, nationality, age, and tenure at the company. That is, all the nations represented on the teams were included in the interviews, which were conducted in all locations (Australia, Brazil, Jamaica, Spain, Suriname, and the U.S.). Interviews were audio- 
recorded and transcribed, resulting in 2280 doublespaced pages of text.

We were also invited to attend the conference calls and face-to-face meetings (the primary forms of interaction for many of the teams) held by the teams during the study period. Members from each location were expected to participate, but that did not always happen. Team facilitators convened the calls and most adhered to an agenda, with each location's sharing of updates as one of the consistent goals for calls. We recorded all conference calls held by these global teams during a six-month period, for a total of 27 calls across nine teams. On average, each call lasted $50 \mathrm{~min}$. One of the researchers listened to these calls, recorded them, and transcribed the discussions. We also observed face-to-face interactions for 22 of the teams, across all the national locations represented on the teams, with two researchers taking copious notes during these meetings, comparing and integrating the notes following the meetings. This resulted in an additional 1134 double-spaced pages of text (average transcript length per meeting was 42 pages). Finally, we examined archival data for the teams, including team websites, postings in the knowledge repositories, and meeting minutes. Although we did not have all three sources of qualitative data across all teams, we were able to obtain at least one source of qualitative data for all 31 teams included in the final sample (see below).

\section{Study 1. Analysis}

The qualitative data were analyzed initially using a grounded theory (Strauss \& Corbin, 1994) approach, but then proceeding from open coding to axial coding and selective coding (Saldaña, 2013). This involved a systematic set of data analysis procedures that assisted in the inductive development of theory from the data (Glaser, 1992). We engaged in an ongoing analysis and interpretation of the data with a goal of recognizing patterns and interrelationships between the phenomena of interest, and using the constant comparative method to move iteratively between data and emergent theory (Strauss \& Corbin 1990).

The transcripts and notes were entered into Atlas.ti, which was used to create a codebook and assign codes, create memos to facilitate understanding of, and links between, codes in the data, keep track of code frequencies, and examine excerpts related to particular codes. Because the team members' experiences of formalization could be located in answers to many of the interview questions and across an entire call, line-by-line coding was employed in order to "[reduce] the likelihood of imputing [researcher's] motives ... to respondents and collected data" (Charmaz, 2008: 94). We began by interpreting each individual's experience, and then aggregated those experiences to the team level in order to characterize each team. This allowed for comparisons both within the team (individual differences) as well as across the teams.

The analyses of these data followed three steps. First, one of the authors and a trained research assistant divided the transcripts and coded them using the logic of open coding, which Strauss and Corbin (1990: 61) described as "the process of breaking down, examining, comparing, conceptualizing, and categorizing data." Decisions about coding and categorizing data were made continuously during the cyclical process of analysis and interpretation. The two coders initially coded five transcripts each, and then met to develop a preliminary code frame, which was continuously refined thereafter. Codes were derived inductively from the transcripts, discussed, and agreed upon by the coders to generate multiple perspectives and alleviate researcher bias.

Second, we conducted axial coding as an intermediate step, defined as "a set of procedures whereby data are put back together in new ways after open coding, by making connections between categories" (Strauss \& Corbin, 1990: 96). In this step, we aggregated raw codes and looked for relationships between them. As a third step, we engaged in selective coding to identify broader themes and dimensions that would form our emergent theoretical structure. This step involved understanding and integrating smaller individual categories as pieces of a larger core category to produce an organizing scheme (Strauss \& Corbin, 1990) to enable further systematic thinking about the phenomenon under study. These categories and their interrelationships formed the basis for our emergent theoretical insights and our hypothesis development.

Throughout this three-step process, we moved iteratively back and forth between theory and data by comparing insights from the data with the literature and vice versa so that each informed the other, as is common in qualitative analysis. At each step, results were discussed among the research team to enable joint interpretation and ensure analytical trustworthiness (Lincoln \& Guba, 1985; Corley \& Gioia, 2004). We coded until we reached "theoretical 
saturation" in which no new codes or insights emerged from the data (Glaser \& Strauss, 1967).

\section{Study 1. Coding results}

In the open coding phase, 19 codes emerged which we subsequently grouped into six higher codes (see Table 1). These included formalization (comprised of the codes for membership, scheduling, rules, and norms), meeting management (agenda, facilitation, and technology use), phases of team work (initial setup, core task work, and implementation), knowledge processes (comprised of dyadic knowledge sharing, multi-party knowledge sharing, knowledge integration and codification), meaning (identification with the team, task importance, agency and autonomy, and meaningfulness), and team outcomes (innovation, best practice sharing, and accomplishing objectives in a way that is responsive across locations).

Analysis of the content of these six higher order codes resulted in three primary themes that highlight the importance of considering not just the level (or amount) of formalization, but also the content (the how and what) of the formalization, including the specific way in which formalization was enacted in the teams, briefly summarized here and to be elaborated upon below. The first theme that emerged was that that timing and sequencing affected whether formalization was perceived as enabling knowledge sharing and effective locationresponsive operational improvements. The second theme that emerged was the importance of multiparty interacting. When members were able to orchestrate formalization such that it allowed for multi-party interaction and collective understanding across locations, it was experienced as enabling effectiveness. Finally, the third theme that emerged was that formalization was viewed as enabling when members viewed it as instrumental in establishing the team as source of meaningfulness and effectiveness. When members could utilize formalization to create work that was perceived as important or meaningful, both from the perspective of themselves and others outside the team across locations, then it was perceived as helping the team to be effective. Importantly, however, there were individual differences in terms of how this was perceived.

\section{Study 1. Themes}

\section{Timing and sequencing}

Interviewees indicated the importance of when and how formalization occurred, specifically whether the formalization pertained to initial set-up of the team or specific projects, as compared to pertaining to subsequent interactions; such timing and sequencing has not been the focus in prior literature. Formalization in the initial set-up of the team or projects consisted of the specification of annual objectives and/or specific meeting deliverables and milestones, pre-meeting agendas, and schedules of meetings. These elements were often established early in a project, and served as a guide for what unfolded in the remainder of the year. Formalization also developed during subsequent interaction, comprising rules and procedures which governed how meetings unfolded in situ, including turntaking norms and the nature and frequency of the interactions inbetween meetings. Importantly, members responded favorably to formalization which occurred during set-up, but not to formalization that occurred in subsequent interaction. In fact, they reported feeling constrained, often even annoyed, when formalization prescribed the flow of knowledge during meetings or affected flexibility of knowledge exchange inbetween meetings.

Across respondents, clearly stated team objectives, explicit agendas, and regularly scheduled conference calls were perceived favorably because they assisted in establishing a routine for connections; an absence of these elements of formalization were viewed as impediments to knowledge sharing and effectiveness. Presence of formal objectives and pre-determined agendas reportedly served to orient members toward prioritizing the work of the team and fulfilling one's responsibilities. As an example, one member commented on the importance of an agenda that incorporates the objectives, yet allows for issues to arise inbetween meetings:

There's an annual agenda that matches with our objectives, that's in our annual plan. So we have the annual plan, and that has a strategy and objectives in it. Then, each meeting agenda has those headings and then we add to it on a monthly basis, depending on what has happened in the past month, that's either gone through the discussion board or through email contact or refinery bulletins, and that's aligned with the strategy of where we're heading. So, it's structured at first, but in between meetings, it's flexible, because it needs to be, because things evolve throughout the year. 
Members of other teams expressed confusion and exasperation that the team did not have such objectives. As one member commented: "I am not sure, we might have some. ... But I don't know what they are. The reason for this team is confusing."

The presence of regularly scheduled conference call meetings was also a significant positive factor for the team members' experience of formalization. Members of teams with pre-scheduled and regularly held meetings cited higher expectations and more consistent contributions. One of the interviewees stated that having conference calls on the calendar meant that the work of the team was more "immediate, an opportunity" and that it was a way to "expose the work of the team" and "generate a good, healthy energy" around them. Generating "healthy energy" in global teams is a common challenge documented in team literature (Gibson \& Gibbs, 2006). One member explained:

One of the dilemmas of the [team] is that, while you're dedicating time to it you also have today's bacon to fry, you have today's things to do, so that's always a dilemma. You sometimes feel split; sometimes you are trying to hold down the proverbial fire.

In contrast, when the free flow of ideas during conversations that occurred within meetings was curtailed by an overly rigid schedule, formalization was not experienced favorably. Said one member, "There is a schedule that always we follow without any change-it's very restricting." Members appreciated time to informally and spontaneously engage in conversation, both during and after meetings. One member said, "Sometimes we call each other and exchange some information. ...not formally, but in this case informal and more immediate, this is very helpful, you know." A member of a team that tended to hold very scripted meetings with tight agendas went so far as to describe a "paranoia" around being accountable for the time spent in the meetings. As explained by one interviewee:

\footnotetext{
And often when you have those sort of [free flowing] conversations something will come up. Like, "We've seen this, what do you think?" Whereas, if you're invited on for a specific purpose, generally it's not that helpful... it's all tied in and restricting. So, yeah, so I haven't been involved in calls for quite a long time.
}

Hence, our analysis allowed us to extend theory on formalization as a tool by which MNOs manage tensions between integration and responsiveness, in that our data suggested the importance of a temporal element. Formalization mandated by the organization during set-up that included objectives, agendas, and regularly scheduled calls facilitated knowledge sharing and effectiveness and was perceived favorably by members in that it enabled knowledge sharing in the team; the absence of these aspects of formalization was viewed as an impediment. When and how formalization occurred appeared to be nearly as important as the degree or level that it occurred, indicating current theorizing must include timing and sequencing of rules, procedures and norms to understand how formalization contributes to outcomes for organizations and individuals.

Multi-party interacting for collective understandings A second theme that emerged from the interviews pertained to the role of formalization in determining the nature of interactions in the teams. Some attempts at formalization resulted in meetings being devoted to formal "presentations" in which much of the agenda was dominated by a single individual describing a particular practice. As mentioned above, there was variance in the use of the technologies across teams. Certain forms of communication, such as email, were less apt to be shared with a larger audience, and instead used for one-on-one exchanges. Some facilitators showed a preference for these channels because they could be easily and formally documented, but as a consequence did not simultaneously engage representatives from across locations. Scholars who have addressed technology use in global teams argue that features such as synchronicity and richness (Kirkman \& Mathieu, 2005) can enhance team processes. Our analysis extends these perspectives by indicating that the way in which team formalization is enacted using these different features determines both team and individual outcomes, through its role in facilitating the types of interaction necessary for knowledge processes, and in particular, for developing collective understanding of each location represented on the team. For example, one team member explained:

[Our regularly scheduled meetings] are very helpful for exchanging information, figuring out what's going on with the different plants. Then people can ask questions everyone is asked for feedback. It's important to call on people, too - good way to make sure everyone is still there and paying attention. 
Multi-party interaction to build collective understanding was important because it facilitated best practice identification, development, and codification that constituted the knowledge sharing in the teams, more so than dyadic interaction. In particular, it enabled the views of all locations to be heard, and this resulted in best practices that were responsive to the unique features of the locations (i.e., "location-responsive"). A member described this aspect of the multi-party interaction like this,

\begin{abstract}
Sometimes on the calls you get people who disagree, people have different points of view - no conflict really, but there is disagreement. Different refineries have different resources, different equipment, some different needs. So you have to consider that... it's important to manage it, to address issues, to talk to people, know what they think - what they say and address it in that conversation.
\end{abstract}

In contrast, interviewees from less effective teams tended to highlight the value of one or two people as direct contacts: "I was fortunate to have met [the facilitator] who kind of gave me an introduction to a person I can actually contact. I did get some information that way." In another team in which primarily dyadic email exchanges occurred, an interviewee said,

Exchange, it's never actually in a way that everyone can see it. So, you know, we may have an objective for [the team], and then someone may be trying to discredit or to disagree with that, but it won't occur in a constructive way. Often destructive things occur in the shadows, where people are speaking offline separately, and then they don't actually relay that opinion back into the team where everyone can see it.

Illustrating how these dyadic interactions impede knowledge sharing activities of the teams, and hence best practice development, another interviewee stated,

\begin{abstract}
Things are still done on the side, rather than as a team. It's done by email, or it's done by two in a meeting and then minutes don't make it to the best practice website. So there are a lot of gaps in the best practice, and so we really need to try to steer everyone through that and make it a focal point for discussion, information, and so forth, on calls. I think people probably don't do that as much.
\end{abstract}

Other members indicated how important it was to be able to "continue the conversation" after a meeting, so that key points of clarification could be discussed, and explained that it was through these informal connections that you can "maintain and keep the team alive and useful for everyone." In some teams, interaction between meetings was rare, because there was an explicit expectation that the work of the team would be circumscribed and limited to the meetings.

\section{Establishing the team as source of identity, meaningfulness and effectiveness}

A final theme that emerged pertained to the role of formalization in establishing identity and meaning. In the context of the organization we studied, members of the global teams had operational roles, and held membership in other teams within their own location, as well as felt affiliation with their profession and with their national context. Prior research has indicated that a key to helping members navigate these multiple affiliations is the establishment of a team identity (Gibson, Gibbs, Stanko, Tesluk, \& Cohen, 2011). Extending this prior work, our interviewees indicated that formalization could help a team solidify an identity, such that its members and others outside the team perceive it as a unified whole; when it performed this function, then formalization was perceived by members as contributing to both team effectiveness and the meaningfulness of work conducted in the teams.

We found it intriguing that the language used to describe the teams by members and those outside the team across the different locations perpetuated and reinforced the view of the team as a meaningful entity. Some of the teams in our sample gained a word-of-mouth reputation, and hence an identity, as being a "good team." In these teams, members referenced the team as " $w e$ " and those outside the team referred to the team as "they." So, team identity actually became visible through the eyes of others. This tended to occur when formalization was high, that is, when the team rules, procedures and routines were clear and adherence to them was visible to members and to outsiders. Said one member, "Without [regular] calls, there is really nothing that makes up a team... So, there is no common identity."

Such an identity was distinct from the word-ofmouth reputation of less formalized teams, which were not referred to as "they". Instead, when commenting on these teams, interviewees might describe a helpful person that they once encountered, that they believe might have been affiliated with the team. The "we" and "they" references were reserved for teams with greater levels of formalization, whereas those with lower levels of formalization were not referenced by others as a team. Said one member of a team with low formalization, 
I don't know if the team has a common identity. It's an interesting question. I guess I'd say, no. We all have lots to do, and people have to do those things. People have to put out fires every day, you can't ask them to worry about this team on top of everything. ... If you have a problem at your refinery, that's what you worry about, not other stuff.

Interestingly, those teams well known throughout the organization also tended to have members that personally identified as a member of the team. Hence, teams whose rules and procedures were clear became known as coherent entities, and their identity in the eyes of outsiders was strong, while members identified with them to a greater extent. Illustrating the link between having team identity and knowledge sharing, another member commented,

I would say we have an identity as a group, sure. If you are in [name of team], you are [team] anywhere. We know what we are working towards, and each [team] member realizes that there is meaning and value in the [team], value for your plant. Each plant location benefits. There is incentive to participate because you know you would get something out of it, and the information and advice will help you with your job.

At the same time, some of the same team members who appreciated aspects of the formalization as being conducive to the initial development of a team identity also expressed frustration at the degree to which interaction was constrained, blocking deeper discussion. This occurred alongside members mentioning a sensitivity to having too much of the interaction scripted or mandated from outside the team. For example, one team member said,

They send the agenda previously to everybody, so we know exactly what we'll be talking about, and when you come to the team everything is scheduled, and we just pass through it...there is a lot of careful control over the agenda...it can even be hard to get in a comment and we generally don't have time to go deeply into it, and it is hard to see it as meaningful.

Other interviewees also indicated their preference for an open sharing of each other's 'realities,' and that doing so made their work more meaningful:

When we can do it right, the team allows you to experience lots of different realities, because the regions are different, the cultures are different, the raw material is different, and you can experience lots of different problems and solutions. It is meaningful in the end because we are thorough in knowledge development.
There was also recognition that members (even within the same team) had very different priorities, needs and expectations for the team, which may coincide with individual differences such as personality. For example, one interviewee commented:

\begin{abstract}
There are widely divergent differences in what people see as important in different parts of the world. Many may not be aligned with belonging to a global team because their world is much more focused, much more task-oriented, managing the project of doing a certain job or $\mathrm{X}$ number of jobs. They're not generally inclined to have a lot of chit-chat about stuff that, you know, is possibly going to benefit the team as a whole.
\end{abstract}

It was evident that, for some team members, the team was an important source of meaning, such that the manner in which formalization was enacted contributed to the meaningfulness of their work, in that it encouraged and supported achieving a state of integrated wholeness, as well as a pride in, and significance of, one's activities (Dimitrov, 2011; Barrick, Mount, \& Li, 2013), which has been found to correlate with factors such as life satisfaction, happiness, and work enjoyment (Bonebright, Clay, \& Ankenmann, 2000). One team member said this:

I think the team works well because we prioritize... we work out what people should be working on, involve them... we go to a lot of trouble to engage people and really once you've got all the right people and you're working on the right things, people want to be part of it; they want to do it because it's their problem.

\section{Another member commented,}

As soon as you see the importance of a [team] you always intend to be more a part of it. So at the beginning it's the curiosity to know what's happening, and then you are... you'll see that it's important that you can share your work, you can share knowledge, you can share experience, so you'll start to join a [team] and be more part of it you'll try to participate more.

These links between team formalization and the establishment of the team identity as a source of meaningfulness of the work, even given individual differences on the team have yet to be investigated. Our findings provide evidence that formalization can be a source of team identity and meaning and, in doing so, enhance team knowledge-sharing processes and the meaningfulness of the work experienced by members. 


\section{STUDY 2. MEDIATING MECHANISMS AND INDIVIDUAL DIFFERENCES}

Based on the insights revealed in our first study, we developed a multilevel research design (team and individual levels) for a second study, and focused our theory building on how formalization, knowledge sharing, and individual personality in global teams contribute to location-responsive team effectiveness and individuals' experiences of meaningfulness of the work. Beyond the level or amount of formalization, our interviews had indicated that the process and content of the formalization (i.e., how formalization occurred and what was formalized) was also important. Specifically, formalization timing and sequencing, formalization for multiparty interaction, and formalization for establishment of team identity also emerged as important global team process, so we incorporated these elements to refine our theorizing. We returned to the literature and combined these findings with prior foundational work to arrive at specific hypotheses which speak to the tensions we noted previously, addressing (1) the level of formalization, (2) the content of formalization, and (3) the experience of formalization for individuals, which could be tested in a more systematic manner. We develop each of these in turn below.

\section{Level of Formalization: Knowledge Sharing for Location-Responsive Effectiveness}

First, our interview results indicated that when the level of formalization contributes to knowledge sharing, this will in turn, promote location-responsive global team effectiveness. Knowledge sharing appears to be the key if formalization is to aid in the balancing of responsiveness and integration. In many MNOs, formalization often acts as a bureaucratic constraint on how, when and what knowledge is shared across different locations. In the context of a global team, this may restrict the potential changes that the team can consider and reduce their motivation or opportunity to look for location-appropriate improvements (i.e., "we don't search because HQ tells us the procedure") (Zellmer-Bruhn \& Gibson, 2006; Ghoshal \& Nohria, 1993). Integration creates tighter coupling and centralization (Weick, 1976) across levels in an MNO, which constrains discretion and can reduce responsiveness at each location (Ghoshal \& Bartlett, 1988).

However, Adler and Borys (1996) have argued that even a high level of formalization has the potential to facilitate the development, sharing, and orchestration of knowledge in organizations, by generating common vocabularies and explicit organizational 'architectures.' Indeed, one mechanism by which formalization has its effects is by assisting members to "parse, route and source taskrelated information based on member roles and responsibilities" (Bunderson \& Boumgarden, 2010: 612). Thus, we argue that, although a high level of formalization runs the risk of too much standardization, which may then stifle new best practice identification, when the formalization improves knowledge sharing, this is likely to facilitate the development of location-responsive effectiveness, such as operational improvements that are appropriate at each location represented on the team. Further, we argue that, given that it is the extent of knowledge sharing that matters and not necessarily the means by which the knowledge is shared, these effects will persist even after controlling for technology use by the teams.

We also acknowledge that, in addition to cognitive mechanisms such as increasing knowledge sharing, a high level of formalization could also influence team effectiveness through social-emotional mechanisms, such as increased cohesion between members. In fact, in some teams, formalization may increase cohesion to the detriment of the team. We saw evidence of this from interviewees, who suggested that rules and templates around meeting management, for example, may have increased the extent to which members were attracted to the team (such that cohesion developed, and they were willing to commit time to meetings), but that these same mechanisms constrained the free expression of ideas during the meeting, and thus were 'restricting.'

Similarly, in their meta-analysis of the performance effects of formal coordination in teams, Courtright et al. (2015) distinguished between effects due to influences on task functioning and those due to relational functioning. Specifically, across 107 samples, they found that formalization (i.e., in their study, the coordination of resources and structuring of workflow) had stronger performance implications through effects on action and transition processes, rather than through effects on interpersonal processes such as the development of cohesion. Formalization encouraged frequent and repeated interaction, which has been shown to result in greater information sharing (Okyhusen, 2001; Rockett \& Okhuysen, 2002). Cohesion is less likely to be an explanatory mechanism for the link 
between level of formalization and global team effectiveness. Rather, we expect that knowledge sharing is the explanatory mechanism which links the level of formalization to subsequent global team effectiveness. In summary, based on both our qualitative findings and support from prior conceptual work, we propose:

Hypothesis 1: Level of formalization in global teams is positively associated with team effectiveness; this relationship is mediated by team members' knowledge-sharing behavior, even after controlling for technology use in the teams.

\section{Content of Formalization: How and What is Formalized?}

First, our qualitative analysis indicated that enacting formalization earlier on in the life of the team or in a project sequence, rather than during interactions, is conducive to knowledge sharing as the teamwork unfolds. Others have noted that teamwork can be characterized as episodic (Marks, Mathieu \& Zaccaro, 2001; Burke, Stagl, Salas, Pierce, $\&$ Kendall, 2006), and that the most effective team processes may be different at each phase of the team's work together (Manser, Howard, \& Gaba, 2008; Mohammed \& Nadakarni, 2014). Research investigating global teams has noted how the structure may evolve and change over time, and that, in the most effective teams, these structures support a sequence of divergence and convergence of members' views (Stahl, Maznevski, Voigt, \& Jonsen, 2010; Maznevski \& Chudoba, 2000). However, this research has yet to uncover specifically the optimal sequencing of formalization across episodes or lifecycle. When it occurs early on, such as in protocols for team meetings, objectives, and milestones, these processes can help the team to get off to a solid start, reducing the need to spend time and effort coming to agreement about basic foundations. Yet, if the way in which formalization is enacted pertains to subsequent interactions, as the team uncovers new needs, priorities, or preferences, then the team may fail to address the most timely and pertinent practices, because these are not brought to the attention of other team members.

Second, our qualitative analysis revealed that formalization which encourages multi-party interaction, rather than dyadic or one-way presentations, results in the building of collective understandings and optimal information flow. Research on situated knowledge has suggested that members' contexts are important to share if collective understandings are to be developed (Cramton, 2001; Cramton \& Hinds, 2005). However, this sort of deep contextualization rarely occurs without multiple iterations and collaborative building upon one another's comments and reactions (Majchrzak, Malhotra, \& John, 2005). Sole and Huysman (2000) demonstrated that localized knowledge remains not only critical to innovation in distributed teams but also provides a necessary feedback loop between local and global. The team members serve in two capacities on global teams: as a representative of their localized context, and as a cross-context collaborator. The local representative serves in this capacity not simply by bringing local knowledge into the global team but also while attempting to generate global solutions, tailoring those solutions to each team member's local context, and sharing these solutions broadly. Effectiveness is facilitated when members mutually take others' perspectives, make sense of them, and integrate these perspectives (Hinsz, Tindale, \& Vollrath, 1997; Hutchins, 1991), but this is difficult to accomplish in dyadic or one-way interactions.

Finally, our qualitative analysis leads us to argue that, when formalization serves to legitimize the team, making it clearly known to members and those outside the team, it becomes a source of identity and meaning, which results in greater engagement in knowledge sharing. For example, identifying a roster for a core set of members, clarifying their roles, and establishing a regular meeting time, creates boundaries around the team, helping the members to know who is on the team and who is not, and this can enable the sourcing and routing of information. Scholars in the team literature have focused on the importance of strong team identification, defined as members' perception of oneness with the team (Ashforth \& Mael, 1998; Dietz, Knippenberg, Hirst, \& Restubog, 2015; Solansky, 2011). Prior research indicates that team identification provides co-workers with common ground and enables sharing of concerns and location-specific knowledge (Hinds \& Mortensen, 2005; Wilson, O'Leary, Metiu, \& Jett, 2008; Gibson et al., 2011), thus leading to knowledge sharing and collaborative interactions (Ren, Kraut \& Kiesler 2007). However, research has yet to investigate the role of formalization in establishing a meaningful team identity for global team members.

Integrating these ideas from our qualitative analysis and prior literature, we propose the following: 
Hypothesis 2: Beyond the level of formalization in global teams, the content of formalization is related to knowledge sharing, such that the more that (1) formalization pertains to initial setup of the team, (2) formalization contributes to multi-party interaction, and (3) formalization serves as a source of meaningful team identity, strengthening the positive relationship with knowledge-sharing behavior.

\section{Formalization and Experienced Meaningfulness of Work}

Our qualitative analysis also indicated that the experience of formalization is likely to vary between team members, in that it contributes to the experienced meaningfulness of their work for some but not others. Specifically, the interviews suggested that personality differences might drive how team members react to formalization, and, specifically, the degree to which they view it as constraining the meaning derived from the work with the team, or enabling that meaningfulness of work. A personality characteristic which could account for this different experience of formalization is personal need for structure (PNS), defined as a "chronic desire for clarity and certainty, and a concomitant aversion to ambiguity" (Elovainio \& Kivimäki, 1999: 210). This concept represents individual differences in preferences for the manifestations of structure (Rietzschel, Slijkhuis, \& Van Yperen, 2014).

Intuitively, it would seem plausible that individuals with a high personal need for structure would garner more meaningfulness from work by participating in a team that has high levels of formalization. Yet, interestingly, our interviews indicated a potentially counter-intuitive effect: when formalization was low, those with a high personal need for structure provided their own means of formalization, highlighting the importance of flexibility and freedom in determining what and how formalization occurs, including the timing, nature, and means of implementing formalization.

That is, our interviews suggested that those with high personal need for structure did prefer structure within the teams, but they found their work more meaningful when they were able to develop it on their own. Such a pattern can perhaps be explained by virtue of the complex nature of the members' roles. Complex jobs, by nature, tend to be relatively unstructured, and members in such roles are often able to introduce structure to their work themselves by, for example, maintaining a personal schedule or proactively developing their own standardised work routines to solve certain problems. If, however, these individuals were instructed by an organisation to implement a particular structure as a means of formalizing and managing their complex work, they may feel unable to enact the structure in a manner in which they prefer it, and hence lose meaningfulness of their work. These relationships were suggested in our qualitative study.

This led us to propose that, when individuals have a high PNS, they may nevertheless view a high level of formalization, including organizational enforcement of collective rules and procedures, as coercive and constraining (Barker, 1993), limiting the meaningfulness they personally derive from work. When the level of formalization is low, and they personally have the freedom to develop their own mechanisms for structuring the work, in dynamic and unique ways, and unencumbered by a mandated set of rules, they find their work meaningful. For example, one interviewee mentioned:

\begin{abstract}
And these calls and our process in them gives us the opportunity to share information and to receive some feedback that can help. Then we can make time to update about research and more theoretical things that generally we don't have so much time during the day to go deeply. I want to make the team something that is nice to be part of it, that I know that I will grow from. When this happens, it's fun to be there and really energetic, and we are recognized as well.
\end{abstract}

For those with high PNS, the importance of the possibility of providing one's own structure within the knowledge sharing environment is underscored by research which has shown the impact of selfregulatory mechanisms such self-efficacy on individuals' motivation to share knowledge in collaborative settings (Quigley et al., 2007). It is only when motivated that collaborators will invest the effort and time required to overcome problems of knowledge transfer and concerns about ownership of information (Hansen, Mors, \& Lovas, 2005). Our qualitative results, combined with this prior research, led us to propose Hypothesis 3:

Hypothesis 3: Team members' personal need for structure will moderate the relationship between the level of formalization enacted by their team, and the meaningfulness of work they experience. The moderation will be such that the relationship between level of formalization and meaningfulness of work will be relatively weaker 


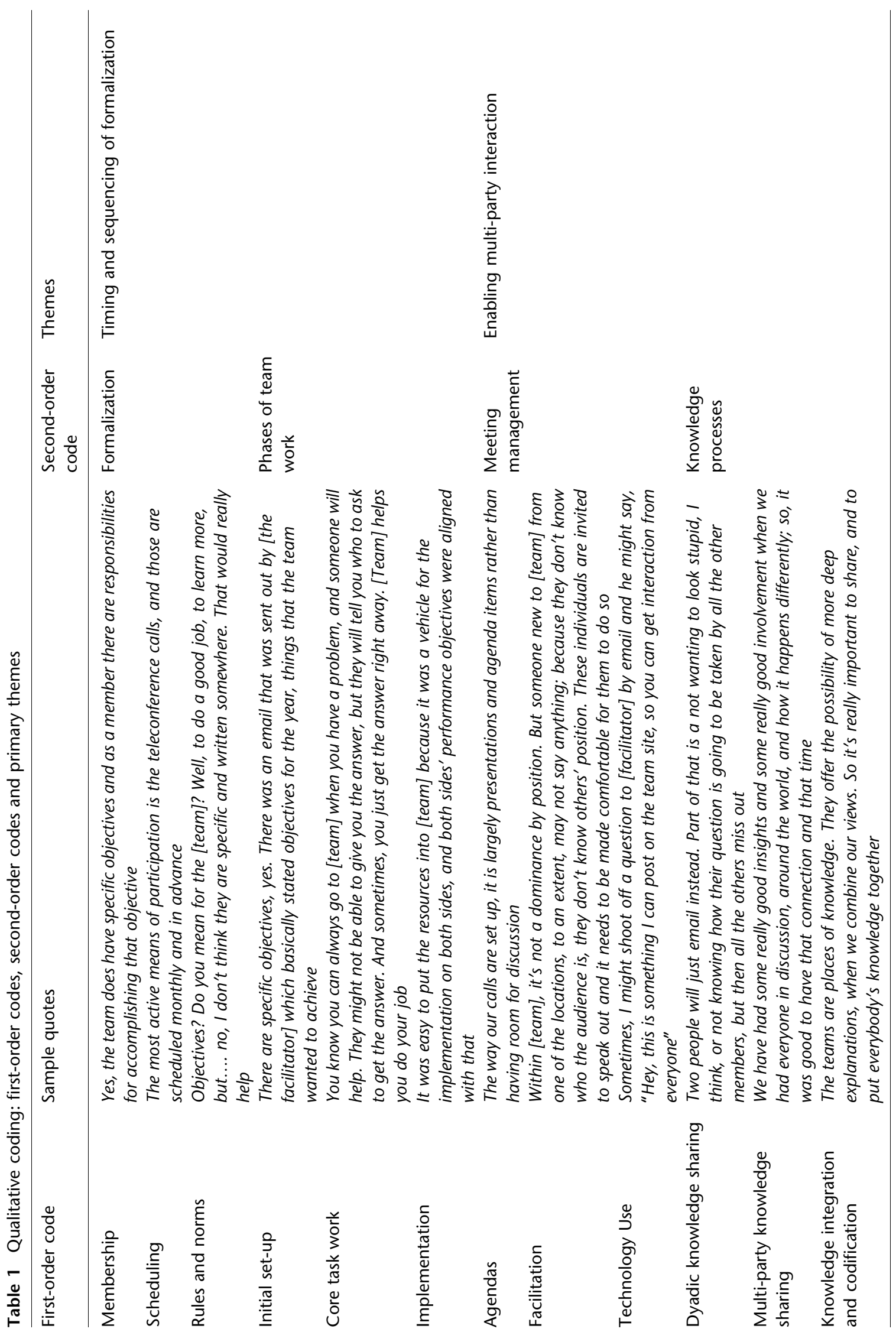




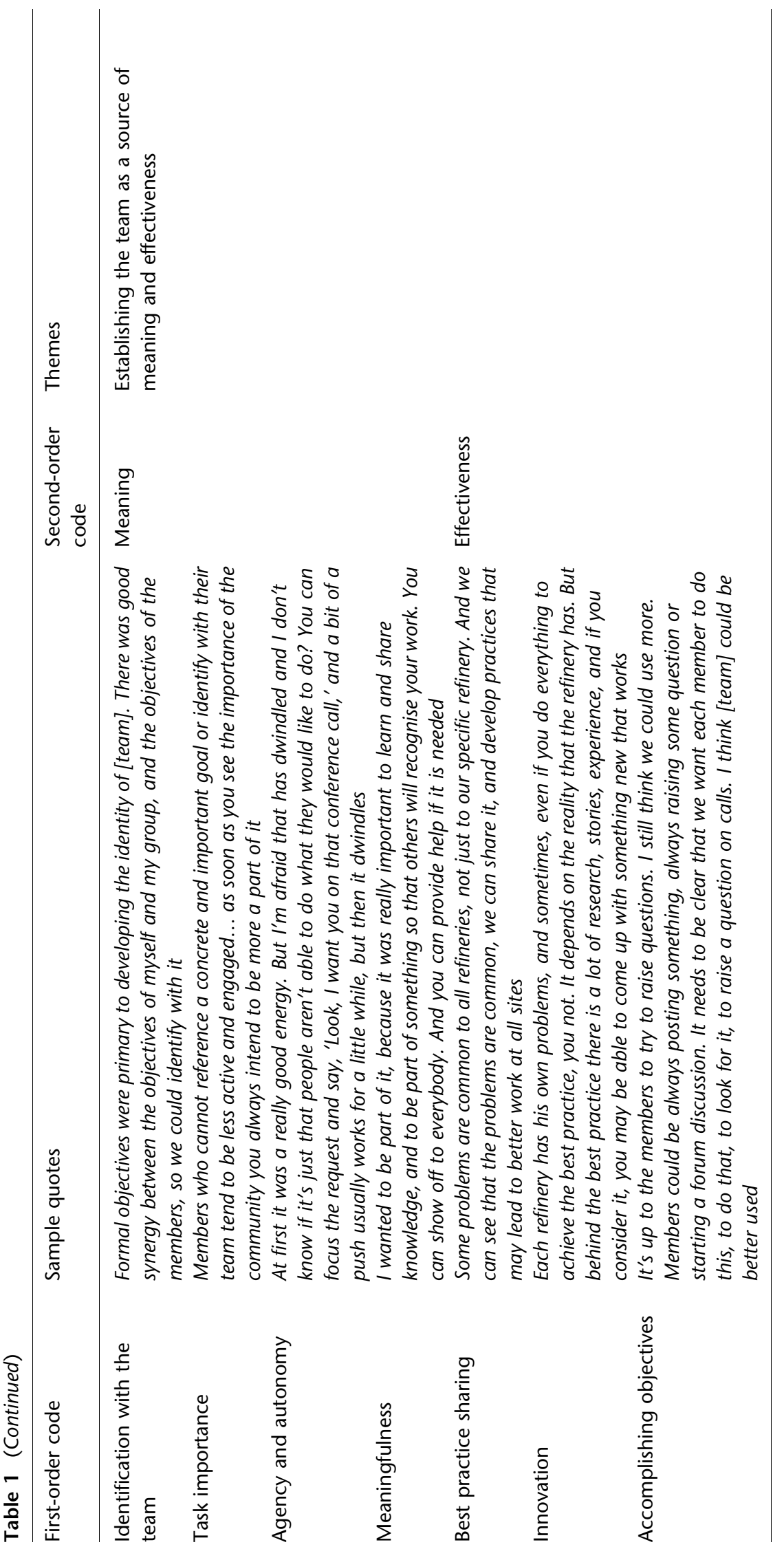


for people with a relatively higher personal need for structure.

\section{Study 2. Methods}

\section{Procedures}

Participants were the same team members as those who participated in Study 1. In July 2013 (Time 1; T1) and December 2013 (Time 2; T2), we emailed members of the 50 global teams within the organization inviting them to complete a survey online. A total of 220 responses were received from members of 44 unique teams at T1. After discarding responses from participants that failed to specify to which team they belonged, those where only one member of a team completed the questionnaire, and those from teams that failed to provide sufficient responses at T2 (see below), the final usable study sample at T1 was 196 participants from 31 teams (mean number of responses per team $=6.3$, $\mathrm{SD}=5.4$, median $=5$ ). Participants reported a mean age of 42.3 years ( $\mathrm{SD}=11.3$ ), and 79.1 percent indicated that they were male. The vast majority of participants held a Bachelor degree or higher-level qualifications (77.3\%), and mean tenure with the organization was reported to be 13.7 years $(\mathrm{SD}=10.3)$.

A total of 262 responses were received from members of 45 unique teams at $\mathrm{T} 2$. After discarding those supplying no team identification, single respondents within a team, and those from participants whose team was not represented by sufficient responses in the T1 survey, the total number of retained responses was 236 (mean number of responses per team $=7.6, \mathrm{SD}=6.1$ ). Of these, 127 were from participants of the 31 teams who had also completed the T1 survey. Across waves of data collection, this equates to an approximate average response rate of $69 \%$ from the population of team members from these 31 teams (not the population of members of all 50 teams). The demographic data observed in the T2 survey were very similar to those observed in the T1 survey (mean age $=42.6$ years, $\mathrm{SD}=10.6 ; 82.0$ percent male; mean tenure $=14.2$ years, $\mathrm{SD}=10.2 ; 77.1 \%$ held a Bachelor or higher degree).

\section{Study 2. Measures}

\section{Overview of measurement approach}

Participants responded to all survey items on fivepoint "Strongly Disagree" to "Strongly Agree" scales. PNS and meaningfulness of work were conceptually and analytically treated as individual-level variables. By contrast, level of formalization, knowledge sharing, and cohesion were rated by individual team members on the extent to which they perceived these characteristics/behaviors in their team. For these variables, referent-shift composition models (where the team was the referent) were specified (Chen, Mathieu, \& Bliese, 2004), as we anticipated that team members would perceive these team-level constructs similarly. Specifically, constructs were operationalized for each team as the mean of the corresponding responses from the teams' members (Chan, 1998; Chen et al., 2004), and we then sought to demonstrate that the team members were providing ratings of the phenomena that are in agreement with one another (Bliese, 2000). A prominent scalelevel inter-rater agreement index is average deviation ( $\mathrm{AD}_{\mathrm{M}(\mathrm{J})}$; see Burke \& Dunlap, 2002; Burke, Finkelstein, \& Dusig, 1999; Smith-Crowe, Burke, Kouchaki, \& Signal, 2013), which provides the average of the absolute numerical distances between the mean rating for a group and the ratings of each member (small $\mathrm{AD}_{\mathrm{M}(\mathrm{J})}$ values are indicative of stronger inter-rater agreement). Smith-Crowe et al. (2013) have provided critical values for $\mathrm{AD}_{\mathrm{M}(\mathrm{J})}$ as a function of the number of response categories and the 'null' distribution chosen to model the absence of within-group agreement. We compared the $\mathrm{AD}_{\mathrm{M}(\mathrm{J})}$ indices that were obtained for formalization and knowledge sharing to several 'critical' values for $\mathrm{AD}_{\mathrm{M}(\mathrm{J})}$ based on three alternative null distributions, namely uniform (critical $\mathrm{AD}_{\mathrm{M}(\mathrm{J})}=0.85$ ), slightly skewed (critical $\mathrm{ADM}_{(\mathrm{J})}=0.69$ ) and moderately skewed (critical $\mathrm{AD}_{\mathrm{M}(\mathrm{J})}=0.49$ ). We also calculated intraclass correlation coefficients ICC(1) and ICC(2) (Chen et al., 2004) for all multi-level variables. ICC(1) provides the proportion of the total variation in individual-level ratings of a phenomenon that is attributable to team membership, whilst ICC(2) indicates the extent to which the observed means can be considered reliable. Both ICC(1) and ICC(2), as maximum-likelihood estimated in Heirarchical Linear Modeling (HLM) for Windows (Raudenbush, Bryk, Cheong, Congdon, \& du Toit, 2011), are reported for multi-level variables.

The degree to which the team was effective was assessed as a team-level variable, rated by the Global Knowledge Manager (GKM) (see below). Finally, we utilized the interviews and conference calls to code the content formalization (i.e., how and what was formalized), specifically whether 
Table 2 Individual and team-level descriptive statistics and intercorrelations between all study variables

\begin{tabular}{|c|c|c|c|c|c|c|c|c|c|c|c|c|}
\hline Variable & Mean & SD & 1 & 2 & 3 & 4 & 5 & 6 & 7 & 8 & 9 & 10 \\
\hline \multicolumn{13}{|l|}{ Team-level variables } \\
\hline 1. Level of formalization (T1) & 3.31 & 0.48 & & & & & & & & & & \\
\hline 2. Global integration (T1) & 3.23 & 0.24 & .39 & & & & & & & & & \\
\hline 3. Knowledge sharing (T1) & 3.69 & 0.38 & .54 & .28 & & & & & & & & \\
\hline 4. Cohesion (T1) & 3.30 & 0.63 & .63 & .34 & .80 & & & & & & & \\
\hline 5. Electronic collaboration Technology use (T2) & 91.20 & 6.89 & .00 & .12 & .25 & .00 & & & & & & \\
\hline 6. Perceived co-presence (T2) & 2.44 & 0.41 & .49 & .23 & .55 & .56 & -.19 & & & & & \\
\hline 7. Formalization for set-up (qual-derived) & 3.13 & 0.66 & .56 & .01 & .47 & .52 & -.23 & .71 & & & & \\
\hline $\begin{array}{l}\text { 8. Formalization for multi-party interaction (qual- } \\
\text { derived) }\end{array}$ & 3.65 & 0.31 & .57 & .19 & .24 & .47 & -.46 & .58 & .52 & & & \\
\hline 9. Formalization for team identity (qual-derived) & 3.66 & 0.41 & .46 & .33 & .52 & .65 & -.20 & .64 & .44 & .57 & & \\
\hline 10. Knowledge sharing (T2) & 3.84 & 0.27 & .68 & .16 & .56 & .60 & -.23 & .66 & .71 & .62 & .69 & \\
\hline 11. GKM-rated team effectiveness & 6.76 & 2.47 & .36 & -.18 & .40 & .23 & -.11 & .32 & .19 & .10 & .17 & .47 \\
\hline \multicolumn{13}{|l|}{ Individual level variables } \\
\hline 1. Personal need for structure (T2) & 3.55 & 0.65 & & & & & & & & & & \\
\hline 2. Meaningfulness of work (T2) & 3.72 & 0.73 & $.20^{\star *}$ & & & & & & & & & \\
\hline
\end{tabular}

Team-level $N=31$. Individual I-vel $N=236$.

Qual-derived this variable was derived from the qualitative analyses, GKM Global Knowledge Manager.

${ }^{*} p<.05,{ }^{* *} p<.01$.

formalization pertained to initial set-up of the team or ongoing rules and protocols, contributes to multi-party interaction for collective understanding, and increases the extent to which the team is seen as a meaningful source of identity.

\section{Level of formalization (T1)}

Participants evaluated the level of formalization within their team via five questionnaire items. Two of the items were originally developed by Bunderson and Boumgarden (2010) to assess formalization within production teams; however, we also incorporated three additional items that captured the formalization of team membership and the conduct of team meetings. The five items were "We follow a very structured work schedule", "Goals and priorities are clearly communicated", "There are rules about who can and can't join this team", "Our team meets according a predetermined meeting schedule (e.g., monthly)", and "The content of our team meetings and discussions is formally recorded and documented (e.g., in agendas, notes and minutes)". Cronbach's alpha of this scale was .72. $\mathrm{AD}_{\mathrm{M}(\mathrm{J})}$ exhibited a mean of $.60(\mathrm{SD}=.19)$ and a median of .59 , and so we felt confident in operationalizing this teamlevel construct via the mean of the responses, since these values were below the values expected from a uniform or slightly skewed null distribution (Smith-Crowe et al., 2013). ICC(1) was .264 and ICC(2) was .612, indicating that team membership accounted for a sizable proportion of the variability (see Mathieu, Aguinis, Culpepper, \& Chen, 2012).

\section{Knowledge sharing (T1 and T2)}

Participants reported on the knowledge-sharing behavior within their team by responding to five team-referent items in the T1 and T2 surveys; the items were adapted from Kirkman et al. (2011). Examples include "[team] members actively share knowledge" and "[this team] calls to members" attention new ideas and/or best practices". Cronbach's alpha was .85 at $\mathrm{T} 1$ and .87 at $\mathrm{T} 2 . \mathrm{AD}_{\mathrm{M}(\mathrm{J})}$ exhibited a mean of .44 at both $\mathrm{T} 1$ and $\mathrm{T} 2(\mathrm{SD}=.24$ at $\mathrm{T} 1, \mathrm{SD}=.20$ at $\mathrm{T} 2$ ) and a median of .48 at T1 and .43 at T2. Again, we felt confident that the means of the individual responses were a suitable representation of team-level knowledge-sharing activities, since these values were below those expected from a moderately skewed null distribution (SmithCrowe et al., 2013). At T1, ICC(1) was .122 and ICC(2) was .425, and at T2, ICC(1) was .040 and ICC(2) was .217.

\section{Cohesion (T2)}

Participants reported on the degree of cohesion within their teams by responding to two referentshift items in the T2 survey, namely "This [team] is very cohesive" and "This [team] sticks together", on a five-point Likert scale (Jehn \& Mannix, 2001). The two items were very highly correlated $(r=.86)$ and so they were combined into a single composite 
scale. $\mathrm{AD}_{\mathrm{M}(\mathrm{J})}$ exhibited a mean of $.49(\mathrm{SD}=.23)$ and a median of .49 . We were thus confident that the means of the individual responses were a suitable representation of team-level cohesion, since these values were below those expected from a moderately skewed null distribution (Smith-Crowe et al., 2013). ICC(1) was .138 and ICC(2) was .484, suggesting that teams tended to vary considerably in their reported cohesion.

\section{Personal need for structure (T2)}

Team members completed four items from the PNS scale developed by Neuberg and Newsom (1993). Example items included "I enjoy having a clear and structured mode of life" and "I find that a consistent routine enables me to enjoy life more". Cronbach's alpha was .77. Being a measure of a dispositional characteristic, this construct was hypothesized to reside at the individual level only, and, as such, inter-rater agreement indices ICCs(1) and (2) were not calculated.

\section{Meaningfulness of work (T2)}

A three-item scale adapted from the work of Spreitzer (1995) was employed to assess the extent to which the work undertaken in the teams was personally meaningful to the team members. The items were "The work I do in my team is very important", "The activities in my team are personally meaningful", and "The work in my team that I do is meaningful", and they formed an internally consistent scale with a Cronbach's alpha of .90. As this construct also captured an inherently individual level phenomenon, we did not calculate withingroup agreement indices.

\section{Team effectiveness}

We obtained ratings of the extent to which the teams developed innovative practices from the GKM 1 month after the completion of the T2 survey. The GKM's role within the organization was to ensure the effective implementation and development of the teams, and this individual was thus the key person within the organization positioned to compare the effectiveness of the different teams. The GKM was blind to the hypotheses of this research and to the results from the team member surveys. In rating team effectiveness, the GKM was asked not to rank the teams but instead to consider each one independently and then to respond to the following three questions by rating each team from 0 to 10: (1) "To what extent have the changes to processes and procedures that have been developed by each team below during [the study period] added value to [the organization]? (e.g., through cost savings, improved yields, reduction in raw materials consumption)" ("not at all" to "a very great extent"), (2) "To what extent has each team below created and implemented new performance practices or standards, during [the study period], that have raised average performance across all locations?" ("not at all" to "a very great extent"), and (3) "To what extent was each team 'active' during [the study period]? That is, to what extent did the team members have routine teleconferences, use their website, create practices and solve problems during [the study period]?" ("not active at all" to "extremely active"). The correlations amongst these three items were very high (ranging from .80 to .86) and as such they were combined into a composite team effectiveness rating (Cronbach's alpha $=.93){ }^{2}$

\section{Content of formalization}

Our final three variables emerged during our qualitative analysis, and were therefore coded using the interviews, conference call transcripts, observational notes and archival data. We began by coding evidence gathered from each individual member, moving line-by-line, noting each individual members' characterization of how formalization occurred and what was formalized.

We found that evidence was consistent within teams, and hence it was easy to characterize a team on each of the three variables. Having seen that there was consistency at the team level in the qualitative codes we derived, we then arrived at a characterization for each team, in the form of a numeric rating, based on the members' characterization within the team. We utilized a scale ranging from 1 to 5 , for each team, to arrive at a single score for the team on each variable. Notions of reliability and validity in qualitative coding are not directly comparable to those in quantitative research (Shah \& Corley, 2006), with experts instead recommending a focus on trustworthiness, and ensuring rigor through credibility and confirmability (Lincoln \& Guba, 1985). We ensured the trustworthiness of our coding by having two coders independently code the teams and show consistency and by corroborating our interpretations with the GKM in the organization. Based on these processes, we proceeded with the team-level assignment of scores on these three variables. 
Table 3 Results of group-level regression analyses of knowledge sharing (at T2) on level of formalization and enactment of formalization (for set-up and for Identity)

\begin{tabular}{llr}
\hline Predictor & $b(\mathrm{SE})$ & $\beta$ \\
\hline Intercept & $1.862(.257)$ & $p$ \\
Level of formalization (T1) & $.162(.071)$ & .284 \\
Formalization for Set-up (qual-derived) & $.158(.051)$ & .384 \\
Formalization for Identity (qual-derived) & $.258(.077)$ & .389 \\
$R^{2}$ & .735 & .004 \\
$R^{2}$-adjusted & .705 & .002 \\
\hline
\end{tabular}

$N=31$ teams.

$b$ unstandardized regression coefficient. SE standard error. $\beta$ standardized regression coefficient. Qual-derived this variable was derived from the qualitative analyses.

Table 4 Results of cross-level regression analyses of meaningfulness of work on formalization and personal need for structure

\begin{tabular}{|c|c|c|c|c|}
\hline \multirow[t]{2}{*}{ Level and variables } & \multicolumn{4}{|c|}{ Models } \\
\hline & Null model (M1) & $\begin{array}{l}\text { Random intercepts, } \\
\text { random slopes (M2) }\end{array}$ & $\begin{array}{l}\text { Intercept as outcome, } \\
\text { random slopes (M3) }\end{array}$ & $\begin{array}{l}\text { Slope as } \\
\text { outcome (M4) }\end{array}$ \\
\hline \multicolumn{5}{|l|}{ Level 1} \\
\hline Intercept $\left(\gamma_{00}\right)$ & $3.723^{* *}(0.047)$ & $3.721^{* *}(0.046)$ & $3.701^{* *}(0.047)$ & $3.701^{* *}(0.046)$ \\
\hline PNS at T2 $\left(\beta_{10}\right)$ & - & $0.250 * *(0.090)$ & $0.249^{* *}(0.090)$ & $0.229^{* *}(0.077)$ \\
\hline \multicolumn{5}{|l|}{ Level 2-"intercept as outcome" } \\
\hline Formalization at T1 $\left(\gamma_{01}\right)$ & & & $0.208(0.107)$ & $0.208(0.107)$ \\
\hline \multicolumn{5}{|l|}{ Level 2-"slope as outcome" } \\
\hline Formalization at T1 $\left(\gamma_{11}\right)$ & - & - & - & $-0.290^{\star}(0.132)$ \\
\hline \multicolumn{5}{|l|}{ Variance components } \\
\hline Within-team variance $\left(\sigma^{2}\right)$ & 0.528 & 0.490 & 0.482 & 0.488 \\
\hline Intercept variance $\left(\tau_{00}\right)$ & 0.000 & 0.001 & - & - \\
\hline Slope variance $\left(\tau_{11}\right)$ & - & $0.044^{+}$ & $0.047^{+}$ & 0.001 \\
\hline Intercept-slope covariance $\left(\tau_{01}\right)$ & - & -0.003 & - & - \\
\hline $\operatorname{ICC}(1)$ & 0.000 & & & \\
\hline - 2 Log-likelihood (deviance) & 518.97 & 508.20 & 504.43 & 500.58 \\
\hline Number of estimated parameters & 3 & 6 & 5 & 6 \\
\hline
\end{tabular}

$N=31$ teams, 236 individuals. Figures in parentheses are standard errors.

ICC Intra-class correlation, T1 Time 1. T2 Time 2.

${ }^{*} p<.05 ;{ }^{* *} p<.01 ;{ }^{+} p<.10$.

For the first variable, Formalization for Set-up, we assigned high scores to the team if the protocols and rules were implemented primarily at the initial set up of the team or projects. For those teams whose members described formalization throughout their interactions, we assigned a low score. Second, evidence that the formalization had created interaction that was collective and collaborative (rather than dyadic or one-way) resulted in high scores on Formalization for Multi-party Interaction. Finally, the greater the extent to which the formalization had been enacted in such a way to establish the team as a meaningful source of identity, the higher the score on Formalization for Identity.

\section{Technology use}

We controlled for technology use in two different ways. First, we asked members to allocate the percentage of their team's time spent on the following means of collaboration, which we had identified as the primary means of collaborating, during the qualitative analysis: face-to-face interaction with the team, conference calls, planning and scheduling tools, email, instant messaging, and knowledge repository (SharePoint). Each individual reported the percentage of time they spent using that means of collaboration for the work of the team (i.e., they allocated $100 \%$ of the team's time across the collaboration options). Employing a direct consensus composition approach (Chan, 1998), these scores were then aggregated to the 
team level by taking the mean across members. Offering evidence of appropriateness of aggregation, we found the average deviation index (median across teams) to be 6 percentage points. That is, on average, team members deviated from the team mean by only 6 percentage points in the extent to which they used the different technologies. To determine extent of technology-dependence, we summed the percent of time spent on the collaborative technologies except face-to-face (i.e., hence this score reflects all work with the team that was not face-to-face). Finally, as a second option for a control variable, we asked respondents the extent to which they experienced a sense of co-presence (Gibson et al., 2011) via six items (e.g., "During your [team meetings], to what extent would you say that the technology makes it seem as though other members of the [team] are right there with you?"), to which participants responded on a 5-point "not at all" - "a great deal scale". This scale was internally consistent, with Cronbach's alpha coefficients ranging from .93 to .96 (mean $=.95)$. The median $\mathrm{AD}_{\mathrm{M}(\mathrm{J})}$ for this variable ranged from .58 to .75 .

\section{Study 2. Results}

Prior to undertaking the substantive analyses, means, standard deviations, and intercorrelations were calculated for all study variables, at the individual and group level, where applicable, and are shown in Table 2. We tested Hypothesis 1 using path analysis with maximum likelihood estimation in Mplus 7.3 (Muthén \& Muthén, 2014). This revealed that formalization at $\mathrm{T} 1$ had a positive effect on knowledge sharing at T2 $(\beta=.471$, $p<.001)$ which, in turn, positively affected GKMrated team effectiveness $(\beta=.680, p<.001)$. The proportion of variance explained in team effectiveness was .223. The indirect effect of formalization on team effectiveness was estimated by bootstrapping 5000 samples and applying 95 percent biascorrected confidence intervals (Hayes \& Scharkow, 2013). This analysis revealed a significant standardized indirect effect of .322 (95\% bias-corrected confidence interval $=.066, .577)$. The overall model fit was good $\left(\chi^{2}(1)=0.117, p=.732\right)$. Thus, in support of Hypothesis 1, GKM-rated team effectiveness was primarily affected by formalization via its impact on knowledge-sharing behaviors. This pattern of results held after controlling for technology dependence or perceived co-presence (standardized indirect effect $=.229,95 \%$ bias corrected confidence interval $=.163, \quad .479 ; \quad \chi^{2}(3)=.129$, $p=.988){ }^{3}$

To investigate socio-emotional mechanisms for these effects as an alternative to the cognitive knowledge-sharing explanation, we replaced knowledge sharing with cohesion in the model. ${ }^{4}$ This allowed us to examine whether cohesion mediated the relationship between formalization at T1 and team effectiveness using path analysis. This analysis revealed that formalization at $\mathrm{T} 1 \mathrm{had}$ a strong positive effect on cohesion at T2 $(\beta=.746$, $p<.001)$ but that GKM-rated team effectiveness was not significantly affected by cohesion $(\beta=.281, p=.090)$. The proportion of variance explained in GKM-rated team effectiveness was .079. The indirect effect of cohesion on team effectiveness was estimated again with 95\% biascorrected confidence intervals derived by bootstrapping 5000 samples, and this analysis revealed a standardized indirect effect of .210; however, its $95 \%$ confidence interval overlapped zero $(-.077$, .496); thus, this indirect effect was not significant. However, the overall model fit was good $\left(\chi^{2}(1)=1.80, p=.178\right)$. These analyses coupled with those above suggest that mediating effects of knowledge sharing represent the better explanatory mechanism for the relationship between formalization and effectiveness.

Hypothesis 2 predicted that, when the content of formalization in global teams is such that it pertains to initial set-up of the team, it contributes to multi-party interaction for collective understanding, and enables the team to be seen as a meaningful source of identity, which will increase knowledge sharing behavior. We tested this by regressing knowledge sharing (T2) onto the level of formalization (as a control) and then entering the three qualitatively-derived ways in which formalization is enacted. This model explained 73.7 percent of the variance in knowledge sharing, though it might be borne in mind that the number of predictors (4) relative to the sample size (31 teams) is large. Formalization for Set-up and Formalization for Identity were both statistically significant predictors of knowledge sharing (both $p=.008$ ), whereas Formalization for Multi-party Interaction was not $(p=.653)$.

Given the small sample size and the moderate correlations within the predictor set (see Table 2), we re-ran the regression analysis but, this time, we omitted multi-party interaction. The results of these analyses are shown in Table 3. Even after controlling for Level of Formalization, the 


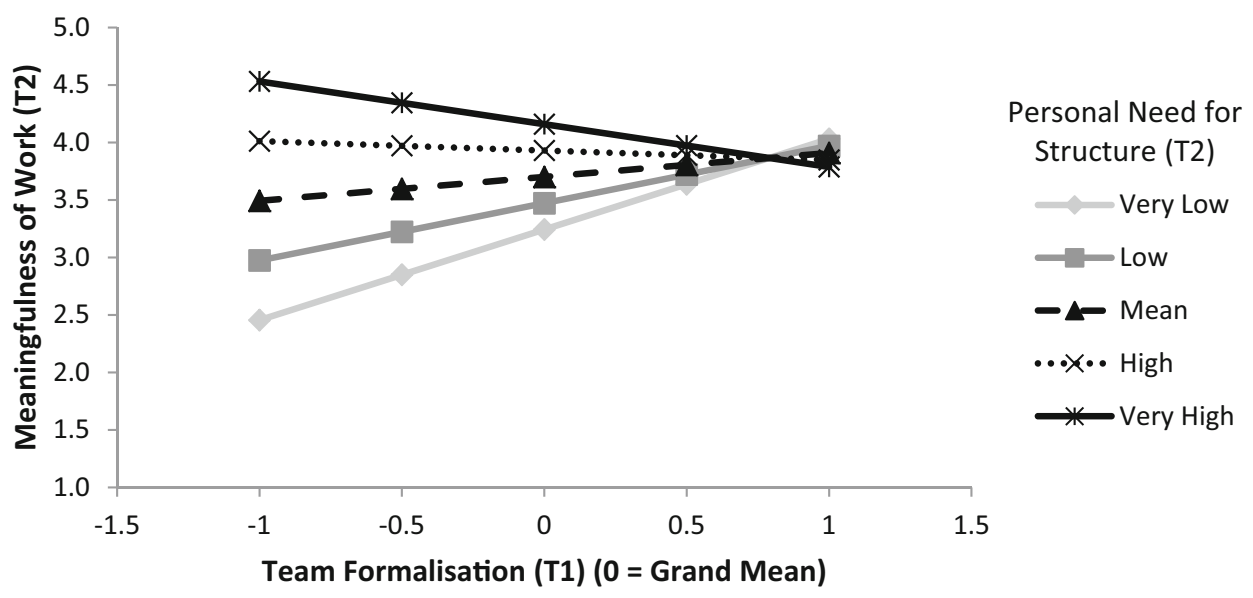

Figure 2 Cross-level moderation of the relationship between formalization and meaningfulness of work by need for structure. For personal need for structure, the steps from very low to very high are 1-point increments on the personal need for structure response scale. These increments, and the range on the $x$-axis, were chosen as they captured almost the full range of observed scores on both variables. $T 1$ Time 1, T2 Time 2.

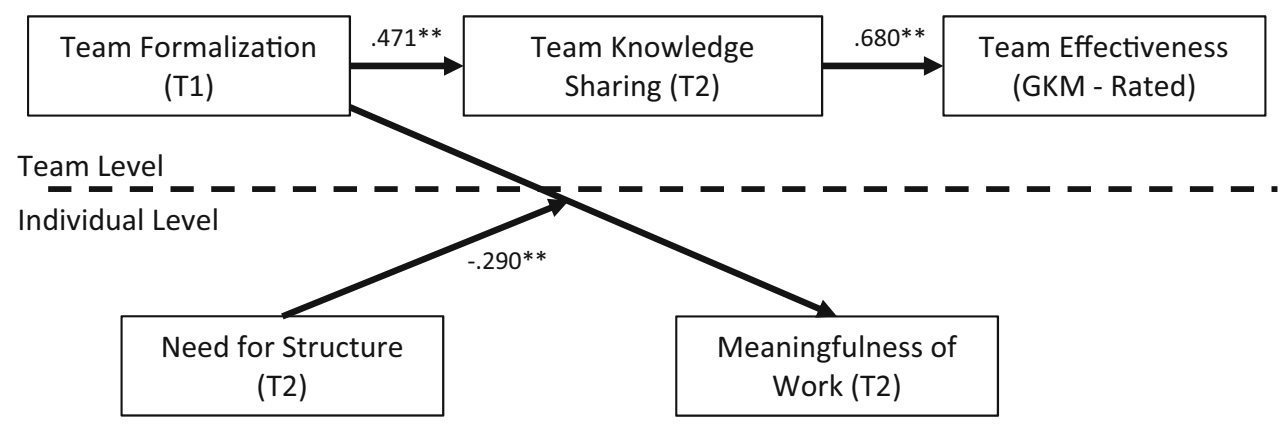

Figure 3 Cross-level relationships investigated. Paths in the team-level section are standardized parameter maximum-likelihood estimates estimated in Mplus. The moderation path in the individual level section is an unstandardized regression coefficient estimated in HLM. In the cross-level analyses, Need for Structure was group-mean-centered and team formalization was grand-mean-centered. The standardized indirect effect of team formalization on team effectiveness was .322 (95\% bias-corrected confidence interval $=.066$, $.577)$, and overall model fit was sound $\left(\chi^{2}(1)=0.117, p=.732\right) .{ }^{* *} p<.01 ., T 1$ Time $1, T 2$ Time 2, T3 Time 3, GKM global knowledge manager.

qualitatively-derived ways in which formalization was enacted (i.e., the content of the formalization, including Formalization for Set-up and Formalization for Identity) were significant and positive predictors of knowledge sharing at T2. This indicates that, apart from the amount of formalization, the extent to which the formalization pertains to set-up and establishes identity predicts knowledge sharing. This partially supports Hypothesis 2, given that we did not find evidence for the expected positive effect of Formalization for Multi-party Interactions on knowledge sharing.

Hypothesis 3 predicted that those individuals with a greater PNS would find their work in the team more meaningful as the level of formalization within the team decreases. To test this hypothesis, we used HLM for Windows (Raudenbush et al., 2011) to examine the cross-level effect of formalization on the meaningfulness of work. This was accomplished through the specification of four models in sequence, and the resultant parameters are presented in Table 4 .

The first model (M1), or null model, modeled meaningfulness of work as a function of team membership only, and the parameters of this model are shown in the first column of Table 4 . M1 yields an ICC(1) for the dependent variable, meaningfulness of work, which was very close to 
zero. This result suggests that almost all of the variation in meaningfulness of work exists at the individual level (i.e., the mean levels of meaningfulness of work were essentially invariant across the teams).

We note here that many multi-level modeling guides indicate that an absence of between-group variance in a dependent variable precludes the need to use multi-level methods to model individuallevel phenomena in nested designs. However, it is important to note that the absence of substantial between-group variance in an individual-level-dependent variable does not preclude the possibility of between-group variance in the strength or direction of individual-level predictor effects on that dependent variable. In the present context, we hypothesized that the strength and direction of the relationship between formalization and experienced meaningfulness of work will vary across individuals, and that this variance can be explained by their own PNS. Thus, a non-zero ICC(1) is not a required precondition for this hypothesis; instead, the precondition that must be satisfied is evidence of substantial between-team variability in the slopes of the PNS-meaningfulness relationships.

To test the variance in the slopes precondition, we introduced PNS as an individual level predictor of meaningfulness of work in the second model (M2). As recommended by Enders and Tofighi (2007) and Aguinis, Gottfredson, and Culpepper (2013) when testing cross-level moderation, we employed group-mean centering, though we note that the pattern of results was nearly identical when grand-mean centering was employed. In M2, we freed the variance in the intercepts $\left(\tau_{00}\right)$ and slopes $\left(\tau_{11}\right)$, with the latter being the parameter of interest. The parameters of this model are shown in the second column of Table 4, and it can be seen that the 'pooled' effect of PNS on meaningfulness of work was positive and significant $\left(\beta_{10}=.250\right.$, $p<.001)$. We also noted that the variance in intercepts was very small $\left(\tau_{00}=.001\right)$, whereas the variance in slopes was relatively large $\left(\tau_{11}=.044\right)$. The associated $\chi^{2}$ significance test for this variance suggested that it was significantly different from 0 at an $\alpha$ of .10 but not significant at the more conventional critical value of $.05\left(\chi^{2}(30)=41.26\right.$, $p=.083$ ). Nonetheless, Aguinis et al. (2013) noted that $\chi^{2}$ tests for variances in slopes tests tend to be underpowered and recommended that researchers proceed with cross-level hypothesis testing when there is a theoretical justification.
Before proceeding with the cross-level interaction test, we first specified a model (M3) which introduced formalization as a predictor of the intercepts. Even though the variance in intercepts was very small, it is important to control for formalization as a 'main effect' predictor in the Level 2 model if one wishes to model its moderating effect on Level 1 relationships. Since the variance in intercepts was small, in M3, we also fixed the residual variance of intercepts to zero. The parameters of this model are shown in the third column of Table 4 . The act of including formalization as a predictor of the intercepts had almost no effect on the other parameters.

In our final model (M4), "Slope as Outcome", we again fixed the intercept residual variance to zero and added grand-mean-centered formalization as a team-level predictor of the PNS-meaningfulness regression slopes. The regression parameter for formalization in the prediction of the slopes in M4 (i.e., $\gamma_{11}$ ) therefore represents a test of Hypothesis 3 , namely that the effect of team formalization on individuals' experienced meaningfulness will vary as a function of the individuals' PNS. The parameters of this model are shown in the fourth column of Table 4, and it reveals that individuals' PNS moderates the relationship between formalization and meaningfulness of work. Specifically, individuals' PNS was positively associated with their experienced meaningfulness $\left(\beta_{10}=.229\right.$, $p<.001)$. However, the higher a person's level of PNS, the less negative the impact of low formalization on their experienced meaningfulness of work $\left(\gamma_{11}=-.290, p=.035\right)$. The relationships revealed by the analyses are plotted in Figure 1, where the relationship between team formalization and meaningfulness of work is shown for five hypothetical individuals with very low, low, moderate, high, and very high PNS. Figure 2 shows clearly that the relationship between formalization and meaningfulness of work depends on individuals' PNS. Specifically, as implied by the regression parameters discussed above, the relationship is positive for individuals with lower PNS and negative for individuals with a higher PNS. Further, it appears that for high levels of formalization, most individuals experience a reasonably high level of meaningfulness, whereas, as the level of formalization of a team drops, the experience of meaningfulness becomes more contingent on the individuals' PNS. This pattern was congruent with that described in Hypothesis 3. Figure 3 shows our full conceptual model with corresponding regression coefficients. 


\section{DISCUSSION}

Our aim in this research was to explore and refine existing knowledge regarding the multi-level impact of formalization in MNOs, by examining the level of formalization, the content of the formalization in terms of when, how, and what is enacted by teams, and the way it is experienced by team members. Such teams are increasingly implemented by MNOs to bring together the best minds around the globe to share knowledge, identify best practices, and bridge locations. However, numerous tensions in implementing these teams are faced by the MNO - they must establish processes that do not over-emphasize integration, at the expense of location-responsive effectiveness. Second, MNOs must create cohesive teams, while also allowing for diverse knowledge to flow. Finally, MNOs need to enable meaningful work for members, while at the same time recognizing individual differences and fulfilling varied needs. Hence, global teams are a precarious organizational form with much potential, but fraught with challenges. Our findings indicate the importance of a multi-level understanding of formalization in these teams to manage the human capital that is housed within them to improve the effectiveness of global work in MNOs. Our findings indicate that, beyond the traditional focus on technology, which is the status quo in the literature, managing formalization is an important path to effective global teams. In doing so, we make theoretical and practical contributions in three areas: addressing tensions in multinational organizations, designing team-based structures for diverse knowledge flows, and facilitating the meaningfulness of work derived by global workers, in light of varied individual needs.

\section{Theoretical and Practical Contributions}

\section{Developing formalization for location-responsive effectiveness to manage tensions}

Prior work has proposed that the key to navigating tensions such as integration and responsiveness (Luo, 2001; Kobrin, 1991; Zellmer-Bruhn \& Gibson, 2006) lies not just in the policies created at the firm level for doing so but also in how they are implemented across the firm, including the managerial capabilities and work processes which enable simultaneous achievement of the dual strategies. Consistent with this, in the global teams we studied, it was not the case that increasing formalization primarily resulted in global integration. Rather, through its impact on knowledge sharing, formalization instead resulted in location-responsive operational improvements, and this was true regardless of whether technology-enabled communications were the primary means of connecting in the teams.

We also found that, even within a single firm that has a defined view of how global teams should operate across their multinational facilities, the extent to which similar teams formalize their operations varied considerably, and not all teams utilized formalization to their advantage to develop location-responsive effectiveness. These results highlight the need to consider not just the level of formalization but also the variety of implementation strategies that teams develop to put the formalization into practice, and to this we add a unique temporal element. Prior work at the firmlevel has addressed temporal strategies for balancing dual tensions, but has primarily described this in terms of the life cycle of the firm (Siggelkow \& Levinthal, 2003, Lavie \& Rosenkopf, 2006; Eisenhardt \& Brown, 1997), such that newly established firms might be in greater need of focus on integration and coordination mechanisms, while mature firms likely need to infuse more local responsiveness and flexibility as they become entrenched over time (Rothaermel \& Deeds, 2004). Our findings indicate tensions can be managed using a different time scale - that of the annual or project planning cycle - as well as highlighting the importance of allowing for fluctuations in these cycles across teams within the same firm. These ideas correspond to evidence indicating that it is when control systems give organizational members flexibility in being able to adapt the system to suit different situations, and opportunities to proactively adapt and improve it, that formalization is enabling (Adler \& Chen, 2011).

The implications for practice are clear. Extending prior work, we show that, when members can implement formalization during the set-up of a team, at the launch of a new project, or at beginning of an annual planning cycle, rather than during conversations in meetings and between them, formalization is conducive to important outcomes for the firm and individuals. In our context, some of this formalization occurred on an annual basis, and took the form of setting formal objectives for the year and, for each meeting, premeeting agendas, and regularly scheduled calls. Yet, formalization that occurred rigidly through the 
entire project or annual cycle, and which members were unable to adjust, was experienced as an unnecessary constraint. Thus, a strategy for reconciling tensions is to consider development processes over time, within the firm at the project or team level, examining formalization as coordination mechanisms evolve, and allowing teams to establish their patterns and norms for work, as they begin to deliver on their objectives. Adjustments by team members themselves as to when formalization occurs is a concrete way to implement this strategy.

\section{Designing teams for diverse knowledge flows across locations}

Although there has been speculation that formalization may create cohesion to a fault within teams by constraining diverse knowledge flows (Courtright et al., 2015; Griffin, Neal, \& Parker, 2007; Crawford \& LePine, 2013), we did not find evidence of such an effect. Rather, we provide strong evidence that it is not the level of formalization per se that contributes beneficially to team outcomes, but the degree to which formalization creates pathways for knowledge sharing. In the global teams in our sample, formalization influenced outcomes primarily through cognitive means, and the mediating effects of knowledge sharing represent the better explanatory mechanism than did cohesion for a positive relationship between formalization and effectiveness.

Research examining formal interventions has indicated that providing 'windows of opportunity' for group members to consider ways to improve their work processes leads to improved team effectiveness (Okyhusen \& Eisenhardt, 2002). Others have speculated that formalization is conducive to team effectiveness when it 'creates a common vocabulary, and thus facilitates interaction among employees who may not know each other personally' (Adler, 2012: 254). Extending this work, we found evidence in our qualitative study that formalization such as rules, procedures and protocols which serve to create collective understanding will improve knowledge sharing processes, particularly when multiple team members are involved. However, we note that future research is warranted as to the specific means by which formalization is linked to knowledge sharing, given the relationships involving multi-party interaction were not as clear in our quantitative study. We also note that a limitation of our study was that many of the teams (although not all) relied on communication technology to interact. Our pattern of results held after controlling for technology dependence or perceived co-presence, but an important extension of our study would be to examine global teams who primarily meet face-to-face, rather than viruallty. We anticipate that this may have implications for relationships involving the multi-party nature of the interaction. Interestingly, multi-party interaction was related to cohesion $(r=.47, p=.008)$. Although cohesion was not, in turn, related to effectiveness as defined in our sample of teams, we know from prior literature that cohesion is important for other team outcomes (Jehn \& Mannix, 2001). For example, perhaps cohesion increases member well-being. Hence, we encourage others to examine the means by which formalization might contribute to global team success through these alternative pathways.

In terms of practice, scholars have shown that factors such as frequency of interaction and a compelling direction for a team increase engagement (defined as mutual focus of attention; Metiu \& Rothbard, 2013). Our findings extend this argument, indicating that it is not just each individual's engagement that is important but also a "collective mind-share" (Klein \& Kleinhaus, 2001) that is crucial to capture. We illuminate that formalization can be used to develop positive team and personal outcomes, including identity and meaning. Contrary to early work on formalization which indicates its coercive properties, we show how rules, norms and procedures can help to establish a sense of "we" in the global team, which in turn contributes to knowledge sharing, and therefore may even be exhilarating for members, spurring valuable contributions to the team's outcomes.

\section{Facilitating the meaningfulness of work derived by global workers}

Importantly, our analyses revealed that individuals differed in their reactions to formalization within the global teams, presenting a challenge of how best to facilitate meaningfulness of work, considering varied individual needs. For those with high PNS, meaningfulness of work was garnered most when formalization was low. Conversely, those with low PNS garnered less meaning when formalization was low than when it was high. Stated another way, if the team does not provide formalization, individuals vary on their need and propensity to provide it themselves. When they are higher on PNS, providing their own formalization increases the meaningfulness of their work. 
In terms of practice, interpreting this result hinges on understanding the preferences and behaviors of the individuals with high PNS. These members appear to prefer to establish their own approach to structuring work, in which case external enforcement of rules and protocols in the form of organizational mandated formalization may interfere with experienced meaningfulness of their work. In order for these members to see the broader significance of their daily activities, they need a hand in how it is structured. Allowing the timing, format and nature of the formalization to be flexible and malleable within the team appears to be critical for these members.

Adler (2012) asserted that it is when employees have the power to influence formalization, participating in how it is used, that it will serve social, productive ends, rather than exploitative ends. We show that this is particularly true when individuals have a high PNS. If such participation and flexibility is not allowed, these members may view the presence of organizationally mandated collective rules and procedures as coercive and constraining (Barker, 1993), limiting the meaningfulness that they personally derive from work. In fact, they may be better able to derive meaning from work when team formalization is low, because they then have the freedom to develop their own mechanisms for structuring the work (Rietzschel et al., 2014), in unique and idiosyncratic ways, unencumbered by a mandated set of rules.

The results discussed above extend prior research which has highlighted the need to consider individual preferences and dispositions as predictors of how well employees respond to working in different team contexts (Kirkman, Gibson, \& Shapiro, 2001; LePine, Buckman, Crawford, \& Methot, 2011; Barrick et al., 2013), as well as in teams with varying levels of formalization (Hirst et al., 2011). This is true irrespective of the degree of technology dependence. In this regard, perhaps the most enabling function of formalization is that it results in a team being perceived as having a clear identity, by those inside and outside the team. Prior research has focused on team identification as a means of encouraging commitment (Hinds \& Mortensen, 2005), and of mitigating the negative effects of incongruent tasks and a lack of goal interdependence (Van der Vegt, Van de Vilert, \& Oosterhof, 2003), but has not been able to pinpoint specific mechanisms for how team identity might be formed. Our interviewees indicated that formalization can point to the team as a meaningful source of identity, and that this improves their engagement with the team.

Thus, we extend work that suggests that identification with a social group contributes to our sense of belonging and engagement with that group (see Ashforth, Harrison, \& Corley, 2008, for a review) by showing that this is likely because, when we identify with our team, for example, we derive great meaningfulness from the work that we do with that team. Our self-concept is defined, at least in part, by our participation in the team, and, when we accomplish work we are proud of with the team, this amplifies the extent to which we find the work meaningful. We view investigating these relationships between formalization, identification and meaning as a promising pathway for future research, and provide additional suggestions in the next section for extending our findings.

\section{Future Research}

We encourage researchers to continue to examine the impact of formalization within global teams, especially in new forms of teamwork (e.g., global communities of practice, multi-team systems) that continue to emerge (Tannenbaum, Mathieu, Salas \& Cohen, 2012). Given how individual differences in PNS impact the experience of formalization, we suggest that future research examine how teams that vary in composition on this dimension might best develop rules, procedures and protocols that facilitate teamwork across dispersed sites, but yet still allow for some degree of flexibility in how formalization is implemented.

In particular, sudden changes to formalization imposed by an organization might result in resistance (perhaps especially so from those with high PNS), but a process of involvement in the design and implementation of formalization may result in a more positive response. Those with a low PNS may be quick to embrace it, but those with a higher PNS might need to be managed differently. The key for researchers would be to become involved right at the point where formalization is introduced and to model the trajectory of different teams over time. Our findings also underscore the promise in further examining team composition, not just in terms of how well members complement each other but also in terms of how well members fit with the design characteristics of the collective to which they belong (Hirst et al., 2011; Mathieu, Tannenbaum, Donsbach, \& Alliger, 2014). Given recent evidence that meaningfulness of work is so central to key work 
outcomes (Carton, 2018), an important responsibility of organizational leaders is to establish the conditions that enhance it. Our findings point to formalization as a key focus for such interventions.

Our results generally support the notion that more formalization is better than less; however, future research might continue to explore how that structure is enacted. Subsequent investigations could examine other aspects of team life in which formalization is most beneficial, such as the vetting of new ideas, exploration of the applicability of ideas, or other conversations which address relatively tacit knowledge. It will also be important to address characteristics of the tasks being performed by the teams, such as the extent to which they involve radical or incremental innovation, or perhaps the extent to which the domain pertains to highly-critical operational processes or less-critical operational processes. Examining the confluence all these features in a large sample of teams in diverse settings would extend our understanding of how they amplify (or potentially detract from) one another. We also view investigation of how various outcomes at multiple levels are inter-related as a promising avenue for future research, particularly if combined with growth modeling to examine trajectories of change in team effectiveness over time (Collins, Gibson, Parker, \& Quigly, 2016).

Finally, we note that our measure of global integration was limited and that our study was conducted in only one firm. We encourage subsequent research which examines the integrationresponsiveness tension across a larger sample of firms, investigating not just the role of mechanisms such as the timing of formalization but also other team- and project-level processes which might serve to balance this tension.

\section{Conclusion}

In conclusion, the dominant narrative emerging from recent empirical research into global teams as a mechanism for integration across the MNO has been one of 'more formalization is better.' By shifting focus to less emphasis on the technologies being used, and more on distinguishing between formalization as designed, as enacted, and as experienced by individuals, our research has demonstrated that there are conditions where more can be even substantially better, such that it is very helpful (and less frustrating) for teams and their members, improving their effectiveness. Our sincere hope is that these more nuanced insights into how formalization enables global teams to function effectively and their members to derive meaning from their work will encourage further research into structural enablement within established and new collective organizational forms. In that way, formalization can be viewed less as a means of constraint and control, intended to keep teams functioning as designed across locations of the MNO and more as a means to help global teams and their members adapt and find meaning, and to enable organizations to manage the global integration-local responsiveness tensions in a complex and challenging world.

\section{ACKNOWLEDGEMENTS}

The authors would like to thank the Australia Research Council Linkage program (Grant \#LP110201117) for funding this research, James Grey for his commitment and perseverance during the project, and our project collaborators Jennifer Gibbs, Yana Grushina, Terence Chia, and Ann Majchrzak, for many wonderful discussions and project assistance. Finally, we thank all of the many participants in the research who generously and enthusiastically gave of their time and insights.

\section{NOTES}

${ }^{1}$ Taken together, these aggregation statistics indicate that members agree very strongly with each other in their assessments of the team knowledge sharing (at T2), but there is a relatively low level of variability across teams in that knowledge sharing (at T2). Despite this, as we show below, knowledge sharing does predict overall effectiveness, indicating that it is an important team process in this context.

${ }^{2}$ We obtained a second assessment of team effectiveness in which team members were asked to respond to eight statements that captured different aspects of the team's effectiveness. Examples included, "[This team] delivers outcomes (products) that are valued by internal and/or external customers", "[This team] serves the purpose it is intended to serve", "[This team] is productive." Participants responded to each item on a 5-point "strongly disagree" to "strongly agree" scale. Cronbach's alpha of this measure ranged from .91 to .94 (mean $=.93)$. The median $\mathrm{AD}_{\mathrm{M}(\mathrm{J})}$ for this measure ranged from .45 to .59 (mean $=.50$ ) suggesting that, generally, the participants shared similar perceptions about their teams' effectiveness. 
Members' ratings were positively correlated with the GKM ratings (e.g., at T1, $r=.40, p=.015$ ), hence corroborating our measure of team effectiveness.

${ }^{3}$ As a final alternative test, we investigated whether formalization and knowledge sharing have a stronger effect on global integration than on team effectiveness, by replacing team effectiveness as our outcome variable with global integration. Participants reported on the extent of global integration in the firm by responding to three items adapted from the work of Takeuchi, Shay, and Li (2008): "To what extent does [the organization]... "Contribute to consistency in processes across locations/refineries?", "Ensure that there is integration across locations/refineries?", and "Mandate uniformity in processes across locations/refineries?" using a fivepoint Likert type scale ( 1 not at all, 5 very great extent) (Cronbach's alpha $=.84$ ). In this test, the

\section{REFERENCES}

Adler, P. S. 2012. The sociological ambivalence of bureaucracy: From Weber to Gouldner to Marx. Organization Science, 23(1): 244-266.

Adler, P. S., \& Borys, B. 1996. Two types of bureaucracy: Enabling and coercive. Administrative Science Quarterly, 41(1): 61-89.

Adler, P. S., \& Chen, C. X. 2011. Combining creativity and control: Understanding individual motivation in large-scale collaborative creativity. Accounting, Organization and Society, 26: 63-85.

Adler, P. S., McGarry, F. E., Irion-Talbot, W. B., \& Binney, D. J. 2005. Enabling process discipline: Lessons on implementing the capability maturity model for software. MIS Quarterly Executive, 4(1): 215-227.

Aguinis, H., Gottfredson, R. K., \& Culpepper, S. A. 2013. Bestpractice recommendations for estimating cross-level interaction effects using multilevel modeling. Journal of Management, 39(6): 1490-1528.

Ahrens, T., \& Chapman, C. S. 2004. Accounting for flexibility and efficiency: A field study of management control systems in a restaurant chain. Contemporary Accounting Research, 21(2): 271-301.

Ashforth, B. E., Harrison, S. H., \& Corley, K. G. 2008. Identification in organizations: An examination of four fundamental questions. Journal of Management, 34: 325-374.

Ashforth, B. E., \& Mael, F. A. 1998. The power of resistance: Sustaining valued identities. In R. M. Kramer \& M. A. Neale (Eds.), Power and influence in organizations (pp. 89-119). Thousand Oaks, CA: Sage.

Barker, J. R. 1993. Tightening the iron cage: Concertive control in self-managing teams. Administrative Science Quarterly, 38(2): 408-437.

Barrick, M., Mount, M. K., \& Li, N. 2013. The theory of purposeful work behavior: The role of personality, higher order goals, and job characteristics. Academy of Management Review, 38(1): 132-153.

Bartlett, C. A., \& Ghoshal, S. 1989. Managing across borders. The transnational solution. Boston: Harvard Business School Press.

Birkinshaw, J. 1996. How multinational subsidiary mandates are gained and lost. Journal of International Business Studies, 27: 467-495. model examined whether knowledge sharing mediated the relationship between formalization and global integration using path analysis. Knowledge sharing was not significantly related to global integration $(\beta=.222, p=.194)$. Further, the indirect effect of formalization on global integration was not statistically significant. Hence, it does not seem to be the case that formalization will affect knowledge sharing, and in turn, result in global integration. Rather, formalization, through its impact knowledge sharing, can instead result in team effectiveness, even when defined as operational improvements that are locally responsive.

${ }^{4}$ Due to the small sample, we opted to specify simple path models separately rather than a comprehensive model with cohesion, knowledge sharing, and global integration.

Bliese, P. D. 2000. Within-group agreement, non-independence, and reliability: Implications for data aggregation and analysis. In K. J. Klein \& S. W. Kozlowski (Eds.), Multilevel theory, research, and methods in organizations: Foundations, extensions, and new directions (pp. 349-381). San Francisco: Jossey-Bass.

Bonebright, C. A., Clay, D. L., \& Ankenmann, R. D. 2000. The relationship of workaholism with work-life conflict, life satisfaction and purpose in life. Journal of Counseling Psychology, 47: 469-477.

Bresman, H., \& Zellmer-Bruhn, M. 2013. The structural context of team learning: Effects of organizational and team structure on internal and external learning. Organization Science, 24(4): 1120-1139.

Bunderson, J. S., \& Boumgarden, P. 2010. Structure and learning in self-managed teams: Why "bureaucratic" teams can be better learners. Organization Science, 21(3): 609-624.

Burke, M. J., \& Dunlap, W. P. 2002. Estimating interrater agreement with the average deviation index: A user's guide. Organizational Research Methods, 5(2): 159-172.

Burke, M. J., Finkelstein, L. M., \& Dusig, M. D. 1999. On average deviation indices for estimating interrater agreement. Organizational Research Methods, 2(1): 49-68.

Burke, C. S., Stagl, K. C., Salas, E., Pierce, L., \& Kendall, D. 2006. Understanding team adaptation: A conceptual analysis and model. Journal of Applied Psychology, 91: 1189-1207.

Caldwell, D. F., \& O'Reilly, C. A. 2003. The determinants of team-based innovation in organizations. Small Group Research, 34: 497-517.

Carton, A. M. 2018. "I'm not mopping floors, I'm putting a man on the moon": How NASA leaders enhanced meaningfulness of work by changing the meaning of work. Administrative Science Quarterly, 63(2): 323-369.

Carton, A. M., Murphy, C., \& Clark, J. R. 2014. A (blurry) vision of the future: How leader rhetoric about ultimate goals influences performance. Academy of Management Journal, 57: 1544-1570.

Cascio, W. F. 2003. Changes in workers, work, and organizations. In I. B. Weiner (Ed.), Handbook of psychology (pp. 401-422). New York: Wiley. 
Chan, D. 1998. Functional relations among constructs in the same content domain at different levels of analysis: A typology of composition models. Journal of Applied Psychology, 83(2): 234-246.

Charmaz, K. 2008. Constructionism and the grounded theory method. In J. A. Holstein \& J. F. Gubrium (Eds.), Handbook of constructionist research (pp. 397-412). New York: Guilford.

Chen, C. J., \& Huang, J. W. 2007. How organizational climate and structure affect knowledge management-The social interaction perspective. International Journal of Information Management, 27(2): 104-118.

Chen, G., Mathieu, J. E., \& Bliese, P. D. 2004. A framework for conducting multi-level construct validation. In F. J. Yammarino \& F. Dansereau (Eds.), Multilevel issues in organizational behavior and processes (Vol. 3, pp. 273-303). Oxford: Emerald Group Publishing Limited.

Collins, C., Gibson, C. B., Parker, S., \& Quigly, N. 2016. Unpacking team dynamics with growth modeling: An approach to test, refine, and integrate theory. Organizational Psychology Review, 6(1): 63-91.

Cordery, J. L., Cripps, E., Gibson, C. B., Soo, C., Kirkman, B. L., \& Mathieu, J. M. 2015. The operational impact of organizational communities of practice: A Bayesian approach to analyzing organizational change. Journal of Management, 41(2): 644-664.

Cordery, J. L., Soo, C., Kirkman, B. L., Rosen, B., \& Mathieu, J. M. 2009. Leading parallel global virtual teams: Lessons from Alcoa. Organizational Dynamics, 38(2): 204-216.

Corley, K. G., \& Gioia, D. A. 2004. Identity ambiguity and change in the wake of a corporate spin-off. Administrative Science Quarterly, 49: 173-208.

Courtright, S. H., Thurgood, G. R., Steward, G. L., \& Pierotti, A. J. 2015. Structural interdependence in teams: An integrative framework and meta-analysis. Journal of Applied Psychology, 100: 1825-1846.

Cramton, C. D. 2001. The mutual knowledge problem and its consequences for dispersed collaboration. Organization Science, 12: 346-371.

Cramton, C. D., \& Hinds, P. J. 2005. Subgroup dynamics in internationally distributed teams: Ethno-centrism or crossnational learning? Research in Organizational Behavior, 26: 233-265.

Cramton, C. D., \& Hinds, P. J. 2014. An embedded model of cultural adaptation in global teams. Organization Science, 25(4): 1056-1081.

Crawford, E. R., \& LePine, J. A. 2013. A configurational theory of team processes: Accounting for the structure of taskwork and teamwork. Academy of Management Review, 38(1): 32-48.

Devinney, T. M., Midgley, D., \& Venaik, S. 2000. The optimal performance of the global firm: Formalizing and extending the integration-responsiveness framework. Organization Science, 11: 674-695.

Dietz, B., Knippenberg, D., Hirst, G., \& Restubog, S. L. 2015. Outperforming whom? A multilevel study of performanceprove goal orientation, performance, and the moderating role of shared team identification. Journal of Applied Psychology. https://doi.org/10.1037/a0038888.

Dimitrov, D. 2011. Sources of meaningfulness in the workplace: A study in the U.S. hospitality sector. European Journal of Training and Development, 36(3): 351-371.

Doz, Y., Bartlett, C., \& Prahalad, C. K. 1981. Global competitive pressures and host country demands: Managing tensions in MNCs. California Management Review, 23(3): 63-74.

Eisenhardt, K. M., \& Brown, S. L. 1997. The art of continuous change: Linking complexity theory and time-paced evolution in relentlessly shifting organizations. Administrative Science Quarterly, 42(1): 1-34.

Eisenhardt, K. M., Furr, N. R., \& Bingham, C. B. 2010. Microfoundations of performance: Balancing efficiency and flexibility in dynamic environments. Organization Science, 21(6): 1263-1273.
Elovainio, M., \& Kivimäki, M. 1999. Personal need for structure and occupational strain: An investigation of structural models and interaction with job complexity. Personality and Individual Differences, 26(2): 209-222.

Enders, C. K., \& Tofighi, D. 2007. Centering predictor variables in cross-sectional multilevel models: A new look at an old issue. Psychological Methods, 12(2): 121-138.

Festinger, L., Schachter, S., \& Back, K. 1950. Social pressures in informal groups: A study of human factors in housing. New York: Harper.

Ghoshal, S., \& Bartlett, C. 1988. Creation, adoption, and diffusion of innovations by subsidiaries of multinational corporations. Journal of International Business Studies, Fall: 365-388.

Ghoshal, S., \& Nohria, N. 1989. Internal differentiation within multinational corporations. Strategic Management Journal, 10(4): 323-337.

Ghoshal, S., \& Nohria, N. 1993. Horses for courses: Organizational forms for multinational corporations. Sloan Management Review, 34(Winter): 23-35.

Gibson, C. B. 2017. Elaboration, generalization, triangulation, and interpretation: On enhancing the value of mixed method research. Organizational Research Methods, 29(2): 193-223.

Gibson, C. B., \& Dibble, R. 2013. Excess may do harm: Examining the diminishing returns of external adjustment in team-based collaborations. Organization Science, 24(3): 687-715.

Gibson, C. B., \& Gibbs, J. 2006. Unpacking the concept of virtuality: The effects of geographic dispersion, electronic dependence, dynamic structure and national diversity on team innovation. Administrative Science Quarterly, 51(3): 451-495.

Gibson, C. B., Gibbs, J., Stanko, T., Tesluk, P., \& Cohen, S. G. 2011. Including the " $I$ " in virtuality and modern job design: Extending the job characteristics model to include the moderating effect of individual experiences of electronic dependence and co-presence. Organization Science, 22: 1481-1499.

Gibson, C. B., Huang, L., Kirkman, B. L., \& Shapiro, D. 2014. Where global and virtual intersect: The value of examining both in 21st century teams. Annual Review of Organizational Psychology, 1: 217-244.

Glaser, B. G. 1992. Emergence vs. Forcing: Basics of Grounded Theory Analysis. Mill Valley, CA: Sociology.

Glaser, B. G., \& Strauss, A. L. 1967. The Discovery of Grounded Theory: Strategies for Qualitative Research. Chicago: Aldine.

Griffin, M. A., Neal, A., \& Parker, S. K. 2007. A new model of work role performance: Positive behavior in uncertain and interdependent contexts. Academy of Management Journal, 50(2): 327-347.

Haas, M. R. 2010. The double-edged sword of autonomy and external knowledge: Analyzing team effectiveness in a multinational organization. Academy of Management Journal, 53: 989-1008.

Hansen, M. T., Mors, M. L., \& Lovas, B. 2005. Knowledge sharing in organizations: A relational perspective. Academy of Management Journal, 48: 776-795.

Hayes, A. F., \& Scharkow, M. 2013. The relative trustworthiness of inferential tests of the indirect effect in statistical mediation analysis: Does method really matter? Psychological Science, 24(10): 1918-1927.

Hempel, P. S., Zhang, Z., \& Han, Y. 2012. Team empowerment and the organizational context: Decentralization and the contrasting effects of formalization. Journal of Management, 38(2): 475-501.

Hinds, P., Liu, L., \& Lyon, J. B. 2011. Putting the global in global work: An intercultural lens on the practice of cross-national collaboration. The Academy of Management Annals, 5(1): $135-188$. 
Hinds, P., \& Mortensen, M. 2005. Understanding conflict in geographically distributed teams: An empirical investigation. Organization Science, 16: 290-307.

Hinsz, V. B., Tindale, R. S., \& Vollrath, D. A. 1997. The emerging conceptualization of groups as information processors. Psychological Bulletin, 121: 43-64.

Hirst, G., Van Knippenberg, D., Chen, C.-H., \& Sacramento, C. A. 2011. How does bureaucracy impact individual creativity? A cross-level investigation of team contextual influences on goal orientation-creativity relationships. Academy of Management Journal, 54(3): 624-641.

Hutchins, E. 1991. Organizing work by adaptation. Organization Science, 2: 14-39.

Jansen, J. J. P., Tempelaar, M. P., van den Bosch, F. A. J., \& Volberda, H. W. 2009. Structural differentiation and ambidexterity: The mediating role of integration mechanisms. Organization Science, 20(4): 797-811.

Jansen, J. J. P., Van den Bosch, F. A. J., \& Volberda, H. W. 2006. Exploratory innovation, exploitative innovation, and performance: Effects of organizational antecedents and environmental moderators. Management Science, 52(11): 1661-1674.

Jehn, K. A., \& Mannix, E. 2001. The dynamic nature of conflict: A longitudinal study of intragroup conflict and group performance. Academy of Management Journal, 44: 238-251.

Johnson, J. H., Jr. 1995. An empirical analysis of the integrationresponsiveness framework: U.S. construction equipment industry firms in global competition. Journal of International Business Studies, 26(3): 621-635.

Junni, P., Sarala, R. M., Taras, V., \& Tarba, S. Y. 2013. Organizational ambidexterity and performance: A meta-analyisis. Academy of Management Perspectives, 27(4): 299-312.

Kirkman, B. L., Gibson, C. B., \& Shapiro, D. 2001. "Exporting" teams: Enhancing the implementation and effectiveness of work teams in global affiliates. Organizational Dynamics, 30(1): 12-29.

Kirkman, B. L., \& Mathieu, J. E. 2005. The dimensions and antecedents of team virtuality. Journal of Management, 31 : 700-718.

Kirkman, B. L., Mathieu, J. E., Cordery, J. L., Rosen, B., \& Kukenberger, M. 2011. Managing a new collaborative entity in business organizations: Understanding organizational communities of practice effectiveness. Journal of Applied Psychology, 96(6): 1234.

Klein, J. A., \& Kleinhaus, A. 2001. Closing the time gap in virtual teams. In C. B. Gibson \& S. Cohen (Eds.), Virtual teams that work: Creating the conditions for effective virtual teaming. San Francisco: Jossey-Bass.

Kobrin, S. J. 1991. Empirical analysis of determinants of global integration. Strategic Management Journal, 21(1): 17-31.

Kortmann, S., Gelhard, C., Zimmermann, C., \& Piller, F. T. 2014. Linking strategic flexibility and operational efficiency: The mediating role of ambidextrous operational capabilities. Journal of Operations Management, 32(7-8): 475-490.

Lavie, D., \& Rosenkopf, L. 2006. Balancing exploration and exploitation in alliance formation. Academy of Management Journal, 49(4): 797-818.

LePine, J. A., Buckman, B. R., Crawford, E. R., \& Methot, J. R. 2011. A review of research on personality in teams: Accounting for pathways spanning levels of theory and analysis. Human Resource Management Review, 21(4): 311-330.

Lincoln, Y. S., \& Guba, E. G. 1985. Naturalistic inquiry. Beverly Hills, CA: Sage.

Lubatkin, M. H., Simsek, Z., Ling, Y., \& Veiga, J. F. 2006. Ambidexterity and performance in small- to medium-sized firms: The pivotal role of top management team behavioral integration. Journal of Management, 32(5): 646-672.

Luo, Y. 2001. Local responsiveness: Perspectives from foreign subsidiaries in an emerging market. Journal of Management, 27: $451-477$.
Majchrzak, A., Malhotra, A., \& John, R. 2005. Perceived individual collaboration know-how development through information technology-enabled contextualization: Evidence from distributed teams. Information Systems Research, 16: 9-27.

Manser, T., Howard, S. K., \& Gaba, D. M. 2008. Adaptive coordination in cardiac anesthesia: A study of situational changes in coordination patterns using a new observation system. Ergonomics, 51(8): 1153-1178.

Marks, M. A., Mathieu, J. E., \& Zaccaro, S. J. 2001. A temporally based framework and taxonomy of team processes. Academy of Management Review, 26: 356-376.

Martinez, J. I., \& Jarillo, J. C. 1991. Coordination demands of international strategies. Journal of International Business Studies, 22(3): 429-444.

Mathieu, J. E., Aguinis, H., Culpepper, S. A., \& Chen, G. 2012. Understanding and estimating the power to detect cross-level interaction effects in multilevel modeling. Journal of Applied Psychology, 97(5): 951.

Mathieu, J. E., Tannenbaum, S. I., Donsbach, J. S., \& Alliger, G. M. 2014. A review and integration of team composition models moving toward a dynamic and temporal framework. Journal of Management, 40(1): 130-160.

Maznevski, M. L., \& Chudoba, K. M. 2000. Bridging space over time: Global virtual team dynamics and effectiveness. Organization Science, 11(5): 473-492.

Metiu, A., \& Rothbard, N. P. 2013. Task bubbles, artifacts, shared emotion, and mutual focus of attention: A comparative study of the microprocesses of group engagement. Organization Science, 24(2): 455-475.

Mohammed, S., \& Nadkarni, S. 2014. Are we all on the same temporal page? The moderating effects of temporal team cognition on the polychronicity diversity team performance relationship. Journal of Applied Psychology, 99(3): 404-422.

Muthén, L. K., \& Muthén, B. O. 2014. Mplus: Statistical analysis with latent variables: User's guide (7th ed.). Los Angeles, CA: Muthén \& Muthén.

Neuberg, S. L., \& Newsom, J. T. 1993. Personal need for structure: Individual differences in the desire for simpler structure. Journal of Personality and Social Psychology, 65(1): 113-131.

Okyhusen, G. A. 2001. Structuring change: Familiarity and informal interventions in problem-solving groups. Acdemy of Management Journal, 44: 794-808.

Okyhusen, G. A., \& Eisenhardt, K. M. 2002. Integrating knowledge in groups: How formal interventions enable flexibility. Organization Science, 13(4): 370-386.

Orlikowski, W. J. 2000. Using technology and constituting structures: A practice lens for studying technology in organizations. Organization Science, 11: 404-428.

Pertusa-Ortega, E. M., Zaragoza-Saez, P., \& Claver-Cortes, E. 2010. Can formalization, complexity, and centralization influence knowledge performance? Journal of Business Research, 63(3): 310-320.

Quigley, N. R., Tesluk, P. E., Locke, E. A., \& Bartol, K. M. 2007. A multlevel investigation of he motivational mechanisms underlying knowledge shairng and performance. Organization Science, 18: 71-88.

Raisch, S., \& Birkinshaw, J. 2008. Organizational ambidexterity: Antecedents, outcomes, and moderators. Journal of Management, 34(3): 375-409.

Raudenbush, S. W., Bryk, A. S., Cheong, Y. F., Congdon, R. T., \& du Toit, M. 2011. HLM 7: Linear and nonlinear modeling. Lincolnwood, IL: Scientific Software International.

Ren, Y., Kraut, R., \& Kiesler, S. 2007. Applying common identity and bond theory to design of online communities. Organization Studies, 28(3): 377-408. 
Rietzschel, E. F., Slijkhuis, J. M., \& Van Yperen, N. W. 2014. Task structure, need for structure, and creativity. European Journal of Social Psychology, 44(4): 386-399.

Rockett, T. L., \& Okhuysen, G. A. 2002. Familiarity in groups: Exploring the relationship between inter-member familiarity and group behaviour. In H. Sondak (Ed.), Research on managing groups and teams (Vol. 4, pp. 173-201)., Toward phenomenology of groups and group membership. Bingley: Emerald.

Rosso, B. D., Dekas, K. H., \& Wrzesniewski, A. 2010. On the meaning of work: A theoretical integration and review. In A. P. Brief \& B. M. Staw (Eds.), Research in organizational behavior (Vol. 30, pp. 91-127). New York: Elsevier.

Roth, K., \& Morrison, A. J. 1991. An empirical analysis of the integration-responsiveness framework in global industries. lournal of International Business Studies, 21(4): 541-564.

Rothaermel, F. T., \& Deeds, D. L. 2004. Exploration and exploitation alliances in biotechnology: A system of new product development. Strategic Management Journal, 25(3): 201-221.

Saldaña, J. 2013. The coding manual for qualitative researchers. Thousand Oaks, CA: Sage.

Schreyögg, G., \& Sydow, J. 2010. Organizing for fluidity? Dilemmas of new organizational forms. Organization Science, 21(6): 1251-1262.

Severt, J. B., \& Estrada, A. X. 2015. On the structure and function of group cohesion. In A. X. Estrada, W. B. Vessey, \& E. Salas (Eds.), Team cohesion: Advances in psychological theory and practice. Oxford: Emerald.

Shah, S. K., \& Corley, K. G. 2006. Building better theory by bridging the quantitative-qualitative divide. Journal of Management Studies, 43(8): 1821-1835.

Siggelkow, N., \& Levinthal, D. A. 2003. Temporarily divide to conquer: Centralized, decentralized, and reintegrated organizational approaches to exploration and adaptation. Organization Science, 14(6): 650-669.

Smith-Crowe, K., Burke, M. J., Kouchaki, M., \& Signal, S. M. 2013. Assessing interrater agreement via the Average Deviation Index given a variety of theoretical and methodological problems. Organizational Research Methods, 16: 127-151.

Solansky, S. T. 2011. Team identification: a determining factor of performance. Journal of Managerial Psychology, 26(3): 247-258.

Sole, D., \& Huysman, M. 2000. Knowledge, practice and the role of location. In M. Huysman \& P. van Baalen (Eds.), Communities of practice: $A$ special issue of trends in communication. The Netherlands: Boom.

Spreitzer, G. M. 1995. Psychological empowerment in the workplace-Dimensions, measurement, and validation. Academy of Management Journal, 38: 1442-1465.

Stahl, G. K., Maznevski, M. L., Voigt, A., \& Jonsen, K. 2010. Unraveling the effects of cultural diversity in teams: A metaanalysis of research on multicultural work groups. Journal of International Business Studies, 41: 690-709.

Strauss, A., \& Corbin, J. 1990. Basics of qualitative research: Grounded theory procedures and techniques. Newbury Park, CA: Sage.

Strauss, A., \& Corbin, J. 1994. Grounded theory methodology. In N. K. Denzin \& Y. S. Lincoln (Eds.), Handbook of qualitative research (pp. 273-285). Thousand Oaks, CA: Sage.

Szulanski, G. 1996. Exploring internal stickiness: Impediments to the transfer of best practice within the firm. Strategic Management Journal, 17: 27-43.

Takeuchi, H., \& Porter, M. 1986. Three roles of international marketing in global strategy. In M. E. Porter (Ed.), Competition in global industries (pp. 111-146). Boston, MA: Harvard Business School Press.

Takeuchi, R., Shay, J. P., \& Li, J. 2008. When does decision autonomy increase expatriate managers' adjustment? An empirical test. Academy of Management Journal, 51: 45-60.
Tannenbaum, S. I., Mathieu, J. E., Salas, E., \& Cohen, D. 2012. Teams are changing: Are research and practice evolving fast enough? Industrial Organizational Psychology, 5: 2-14.

Van Der Vegt, G. S., Van De Vliert, E., \& Oosterhof, A. 2003. Informational dissimilarity and organizational citizenship behavior: The role of intrateam interdependence and team identification. Academy of Management Journal, 46(6): 715-727.

Wilson, J. M., O'Leary, M. B., Metiu, A., \& Jett, Q. R. 2008. Perceived proximity in virtual work: Explaining the paradox of far-but-close. Organization Studies, 29: 979-1002.

Weick, K. E. 1976. Educational organizations as loosely cou- pled systems. Administrative Science Quarterly, 21: 1-19.

Wouters, M., \& Wilderom, C. 2008. Developing performancemeasurement systems as enabling formalization: A longitudinal field study of a logistics department. Accounting Organization Society, 33(4-5): 488-516.

Zellmer-Bruhn, M., \& Gibson, C. B. 2006. Multinational organizational context: Implications for team learning and performance. Academy of Management Journal, 49: 501-518.

\section{ABOUT THE AUTHORS}

Cristina B Gibson is Dean's Distinguished Professor of Management at the Pepperdine Graziadio School of Business. Her area of expertise is the nexus of organizational behavior, international management, and cross-cultural psychology. Her work has informed organizational policy, structure, training and development agendas improving operational efficiency, innovation, resource allocation, and well-being, in non-profits, entrepreneurial firms, and large multinationals across over 20 countries.

Patrick D Dunlop is currently affiliated with the Future of Work Institute at Curtin University. His research investigates personality and individual differences in the work context, particularly how they relate to personnel recruitment, selection, and socialisation. His research informs practices to improve recruitment and selection outcomes across work and volunteer settings, and on how work influences the development of our personality through adulthood.

John L Cordery is Provost at Curtin University in Perth, Western Australia. Prior to this, he was Professor of Management within the Business School at the University of Western Australia. Professor Cordery has a PhD in Industrial/Organizational Psychology from the University of Sheffield. His primary research interests are in work design and the effectiveness of groups and teams in organizations. 
Open Access This article is distributed under the terms of the Creative Commons Attribution 4.0 International License (http://creativecommons. org/licenses/by/4.0/), which permits unrestricted use, distribution, and reproduction in any medium, provided you give appropriate credit to the original author(s) and the source, provide a link to the Creative Commons license, and indicate if changes were made.

Publisher's Note Springer Nature remains neutral with regard to jurisdictional claims in published maps and institutional affiliations.

Accepted by Mary Teagarden, Area Editor, 16 December 2018. This article has been with the authors for two revisions. 